IZA DP No. 9088

Does Daylight Saving Time Really Make Us Sick?

Lawrence Jin

Nicolas R. Ziebarth

May 2015 


\title{
Does Daylight Saving Time Really Make Us Sick?
}

\author{
Lawrence Jin \\ Cornell University \\ Nicolas R. Ziebarth \\ Cornell University, \\ DIW Berlin and IZA
Discussion Paper No. 9088
May 2015 \\ IZA \\ P.O. Box 7240 \\ 53072 Bonn \\ Germany \\ Phone: +49-228-3894-0 \\ Fax: +49-228-3894-180 \\ E-mail: iza@iza.org
}

\begin{abstract}
Any opinions expressed here are those of the author(s) and not those of IZA. Research published in this series may include views on policy, but the institute itself takes no institutional policy positions. The IZA research network is committed to the IZA Guiding Principles of Research Integrity.

The Institute for the Study of Labor (IZA) in Bonn is a local and virtual international research center and a place of communication between science, politics and business. IZA is an independent nonprofit organization supported by Deutsche Post Foundation. The center is associated with the University of Bonn and offers a stimulating research environment through its international network, workshops and conferences, data service, project support, research visits and doctoral program. IZA engages in (i) original and internationally competitive research in all fields of labor economics, (ii) development of policy concepts, and (iii) dissemination of research results and concepts to the interested public.
\end{abstract}

IZA Discussion Papers often represent preliminary work and are circulated to encourage discussion. Citation of such a paper should account for its provisional character. A revised version may be available directly from the author. 
IZA Discussion Paper No. 9088

May 2015

\section{ABSTRACT}

\section{Does Daylight Saving Time Really Make Us Sick?*}

This paper comprehensively studies the health effects of Daylight Saving Time (DST) regulation. Relying on up to 3.4 million BRFSS respondents from the US and the universe of 160 million hospital admissions from Germany over one decade, we do not find much evidence that population health significantly decreases when clocks are set forth by one hour in spring. However, when clocks are set back by one hour in fall, effectively extending sleep duration for the sleep deprived by one hour, population health slightly improves for about four days. The most likely explanation for the asymmetric effects are behavioral adjustments by marginal people in spring.

JEL Classification: $\quad H 41,118,131$

Keywords: Daylight Saving Time (DST), BRFSS, hospital admissions, sleep deprivation, Germany, US

Corresponding author:

Nicolas R. Ziebarth

Cornell University

Department of Policy Analysis and Management (PAM)

106 Martha Van Rensselaer Hall

Ithaca, NY 14850

USA

E-mail: nrz2@cornell.edu

\footnotetext{
* We thank Peter Eibich, Tatiana Homonoff, Don Kenkel, Mike Lovenheim, Helmut Lüdtkepohl, Shinsuke Tanaka, Gert Wagner and participants at the Cornell Health Economics, Health Behaviors and Disparities Seminar as well as the GC Winter Workshop at DIW Berlin. A special thank goes to Aline Paßlack for excellent research assistance. We take responsibility for all remaining errors in and shortcomings of the article.
} 


\section{Introduction}

For one century, a simple policy regulation has been affecting more than one billion people in 70 countries around the globe and triggers heated debates among proponents and opponents: "Daylight Saving Time (DST)." First proposed by Benjamin Franklin to save candlelight in a satire letter to the Journal de Paris (Franklin, 1784; Aldridge, 1956), Germany and Austria-Hungary were the first countries to introduce DST during World War I (WWI). On April 30, 1916, Germany introduced DST, or "summertime," by setting the clocks forward by one hour at $11 \mathrm{pm}$. In fall, the clocks would be turned back by one hour again. As such, in summer, people would spend more time with natural daylight in the evening.

The main rationale for the introduction of DST during WWI was to save energy. Several other European countries also introduced DST in 1916; the US followed in 1918. However, after WWI, the unpopular DST was largely abolished again. Next, World War II (WWII) reanimated the old DST idea but, again, it was largely abolished after the end of the war. Finally, the oil crisis in 1973 leveraged the third and most enduring DST wave. Today, all countries in the European Union, the great majority of the US states and Canadian provinces, as well as 40 other countries such as Mexico, Chile, Israel, or Iran set their clock one hour forward in spring and one hour back in fall.

Supporters of this policy regulation point to the fact that people would spend more time with daylight in the evening hours in summer. Since most people prefer to spend their nonsleeping time in daylight rather than in darkness, DST may increase overall welfare. Recent research has identified significant decreases in robberies due the additional evening hour in daylight (Doleac and Sanders, 2015).

In addition, energy conservation is still an argument. For example, starting in 2007, the US has extended the DST period by four weeks with the explicit goal to reduce energy consumption (EPA, 2005). However, several recent studies have heavily challenged the energy conservation argument. They find that energy consumption may actually (slightly) increase as a result of DST, mostly because the savings in electricity for electric light are overcompensated by 
increases in energy consumption for heating and other electronic devices such as air conditioning (Kellogg and Wolff, 2008; Momani et al. 2009; Krarti and Hajiah, 2011; Kotchen and Grant, 2011; Sexton et al. 2014).

One obvious disadvantage of DST regulation is the organizational effort necessary by changing the clocks twice a year (Hamermesh et al. 2008); for example, (i) coordination in professional or private settings, (ii) adaptations in airline, bus and train schedules, (iii) the labor organization in piece-rate producing companies, or (iv) the exertion of sun-related religious practices such as Jom Kippur or Ramadan.

However, in the first place, opponents of the DST regulation point to (primarily) medical studies which presumably identify causal adverse population health effects of spring DST due to "mini jet lags." Existing studies claim to empirically identify increases in traffic fatalities ${ }^{1}$ (Coren 1996a, Hicks et al., 1998; Alsousou at el., 2011), (workplace) injuries (Coren, 1996b; Barnes and Wagner, 2009)², cardiovascular diseases (Janszky and Ljung, 2008; Foerch et al., 2008; Janszky et al., 2012; Jiddou et al. 2013); disruption of sleep (Lahti et al., 2006; Kantermann et al. 2007), and even suicide rates (Berk et al. 2008). ${ }^{3}$ However, all of the studies just cited are noneconomic studies in the fields of medicine, biology, and psychology and typically use very simple before-after identification strategy prone to a series of confounding factors.

Adverse health effects were also the rationale for Russia to abolish DST in 2011. However, after the policy change, many Russians complained about chronic fatigue as well as the loss of daylight during summer, which led Russian president Vladimir Putin to conclude:

\footnotetext{
${ }^{1}$ Competing studies come to diverging results and find no increases or even decreases in crashes (Ferguson et al., 1995; Sood and Ghosh, 2007; Lahti et al., 2010; Huang and Levinson, 2010). Kountouris and Remoundou (2014) and Kuehnle and Wunder (2014) use SOEP as well as BHPS data and find negative well-being and mood effects when focusing on DST in spring and comparing the weeks after to the weeks before DST changes.

${ }^{2}$ Lahti et al. (2011) do not find empirical evidence for increases in occupational accidents.

${ }^{3}$ Other welfare-relevant effects that the literature links to DST are decreases in stock market returns (Kramer et al., 2000; Pinegar, 2002; Kramer et al., 2002, Brahmana et al., 2012), decreases in SAT scores (Gaski and Sagarin, 2011) and increases in cyberloafing (Wagner et al., 2012).
} 
"When Medvedev [the former president] took the decision, he based it on a significant part of the population believing the previous system affected their health and the farming industry. It turned out that there are more people unhappy with the change than those who called for it." (Vladimir Putin, December 15, 2012 at a press conference, Bloomberg, 2012)

More recently in March 2015, Michigan legislator Rep. Jeff Irwin proposed a bill to abolish daylight saving time in the state, citing: "As we have all experienced this week, changing schedules for daylight saving time is stressful and unnecessary. In the days after the spring time shift, there are well-documented increases in road and workplace accidents, as well as heart attacks." As of writing, several other states including Alaska, Missouri, and Texas are also considering similar measures to abolish DST. There continues to be heated political debates on this topic.

This paper makes use of two health datasets that complement each other in an ideal way to study the population health effects of DST: (a) The US Behavioral Risk Factor Surveillance System (BRFSS), and (b) The German Hospital Census. The advantages of exploiting both datasets are the following: First, we present empirical evidence from the biggest American and the biggest European country. In total, the database covers the behavioral reactions of 400 million individuals. Second, each database covers the entire year-not just spring or fall DST clock changes-over the first decade of the new millennium. This allows us to comprehensively evaluate the overall health effects of DST regulation, not just over one specific, but over ten years. Third, both representative datasets carry a very large number of observations which is crucial to be able to control for important seasonal confounding factors while maintaining enough statistical power to identify effects at the daily level. Our estimates are very precise since they rely on up to 3.4 million individual observations in the case of BRFSS, and up to 160 million observations in the case of German Hospital Census. Fourth, the two databases complement each other in terms of content and what we intend to measure. While the BRFSS captures the entire population and contains a rich battery of self-reported health measures that elicit mild(er) DST health effects, the Hospital Census captures severe DST health effects that require inpatient stays. 
Overall, our work yields credible empirical evidence on the population health effects of DST regulation. The two high-quality datasets and state-of-the art empirical methods allow us to analyze health effects of DST regulation more comprehensively and cleanly than ever before. Most importantly, our study overcomes typical data-related drawbacks in existing studies and allows us to disentangle: (i) The day-to-day short-term and immediate impact of changing the clocks from the (ii) net impact on a weekly basis. Moreover, we disentangle important confounding factors such as (iii) weekday effects-clocks are typically changed on Sundays while is it a stylized fact that hospital admissions spike on Mondays (cf. Witte et al., 2005), or (iv) general seasonal effects as well as specific seasonal effects such as Easter Sunday or vacation day effects. In refined effect specifications that intend to test for behavioral adaptions, we (v) stratify the results by individual-level socio-demographics as well as ambient climatic conditions such as temperatures, hours of sunshine, and pollution.

The findings clearly demonstrate that there is little to no empirical evidence that, overall, DST regulation significantly harms population health. First of all, when assessing the health effects of springing forward in time by one hour in spring, one finds no major impact on selfreported health in either tail of the health distribution. The effects are precisely estimated and let us exclude with $95 \%$ statistical certainty that the share of Americans in excellent health decreases by more than 1 percentage point (ppt), or that the share of Americans in fair or poor health increases by more than $1.6 \mathrm{ppt}$. When focusing on the very right tail of the bad heath distribution and inpatient hospital admissions, we also find very little evidence that DST triggers additional hospital admissions by setting the clocks one hour forward on a Sunday in spring.

Second, evaluating the health effects of DST regulation in fall, one detects clear and consistent evidence that health improves in the short-run for four days when people on the margin get one more hour of sleep. We find surprisingly similar pattern in the US BRFSS survey as well as the German administrative hospital data. The data show that the share of US citizens who believe that they are in excellent health increases from 19 to $20 \%$ on days 1 to 4 after the change in fall DST. Similarly, we find a sharp decrease of about 8 hospital admissions per 100,000 population on days 1 to 4 after falling back one hour in fall. Together with evidence 
that many people are permanently sleep deprived (Valdez et al. 1996; Duffy et al. 2001, Duffy and De Gennaro, 2001; Moore et. al., 2002; Roenneberg et al., 2007; Knutson et al., 2007) and the link between sleep deprivation and bad health (Pilcher and Huffcutt, 1996; Pilcher et al., 1997; Pilcher and Ott, 1998; Ferrara and De Gennaro, 2001; Ayas et al., 2003; Taheri et al., 2004; Mullington, et al., 2009), this finding is one of the first quasi-experimental studies showing that sleep may lead to significant, immediate, health improvements for people on the margin to getting hospitalized.

The next section briefly describes the data. More details about the data can also be found in the Appendix. Section 3 outlines the empirical methodology. Section 4 presents and discusses the findings and Section 5 concludes.

\section{Datasets}

\subsection{The US Behavioral Risk Factor Surveillance System (BRFSS)}

The Behavioral Risk Factor Surveillance System (BRFSS) is a large, on-going annual telephone survey of US adults aged 18 or above, administered by the Centers for Disease Control and Prevention (CDC) in collaboration with state health departments. The survey began in 1984 with fifteen participating states, and by 1996, all 51 states (including the District of Columbia) participated in the survey. It covers an extensive set of self-reported health measures and is, by design, representative of state populations. There are more than 3.4 million observations over the period 2001-2010. Our regressions routinely use sampling weights provided by the survey.

For the main analysis, we restrict our sample to six weeks around each of the two daylight savings times-one in spring and the other in fall. The reason for restricting the sample this way is to reduce seasonal effects that are difficult to control for entirely. However, we show that the findings are robust to this using the full sample. There are 799,171 observations in the restricted sample; Table A1 reports descriptive statistics of this subsample. As shown, the dataset includes demographic variables such as age, sex, race, and marital status, as well as the level of education and employment status. 


\section{Construction of Main Dependent Variables}

For our analysis, we focus on people's responses to the standard self-assessed health (SAH) question: "Would you say that in general your health is __?" Table A2 shows the distribution of five answer choices: excellent, very good, good, fair, and poor. The majority of respondents report their general health to be either very good (32\%) or good (30\%), and about 19\% report excellent general health. Less than $6 \%$ of the population report poor general health.

From this, we construct two binary dependent variables of interest: (a) Excellent health, and (b) fair or poor health. The latter variable equals one if the individual responded with either "fair" or "poor" to the general health question, and zero otherwise. In our restricted sample, 19.3\% responded "excellent" general health, and 18.4\% responded with either "fair" or "poor" general health.

In extended model specifications, we exploit six additional measures that capture selfreported (i) poor physical health, (ii) poor mental health, and (iii) insufficient rest. In addition, refined models use three sleep-related questions as outcome variables which have been surveyed in up to nine US states since 2009.

\section{Measuring Daylight Saving Time in the US}

In the US, as of 2015, daylight saving time begins on the second Sunday in March and ends on the first Sunday in November. Time change occurs at 2am, where the clocks are moved forward from $2 \mathrm{am}$ to $3 \mathrm{am}$ in spring and moved back from $2 \mathrm{am}$ to $1 \mathrm{am}$ in fall. Table 1 shows the

various dates of daylight saving time for the years 2001 to 2010. Note that there was a structural change to extend DST in 2007; prior to 2007, DST began in April and ended in October.

Daylight saving time is observed by most states in the US. As of 2015, the states that do not observe DST are Arizona, Hawaii, and overseas territories. Indiana only began to observe DST in 2006. We include observations from non-observing states in our analysis as controls. 


\subsection{German Hospital Admissions Census (2000-2008)}

These data comprise all German hospital admissions from 2000 to 2008. By law, German hospitals are required to submit depersonalized information on every single hospital admission. The 16 German states collect these information and the German Federal Statistical Office (Statistische Ämter des Bundes und der Länder) provides restricted data access for researchers.

Germany counts about 82 million inhabitants and registers the total of about 17 million hospital admission per year. ${ }^{4}$ To obtain the working dataset, we aggregate the individual-level data on the daily county level and then normalize admissions per 100,000 population.

As seen in Appendix B, besides others, the data include information on age and gender, the day of admission, the county of residence as well as the diagnosis in form of the $10^{\text {th }}$ revision of the International Statistical Classification of Diseases and Related Health Problems (ICD-10) code.

As mentioned and discussed in more detail in the next section, for the main models, we restrict the sample to a total of six weeks around the time change in spring and fall. However, in robustness checks we make use of the entire 52 weeks of the year and show that the findings are robust to this sample restriction. The restricted main sample contains 336,604 county-day observations, whereas the full sample counts 1,429,196 county-day observations over 9 years. ${ }^{5}$

\section{Construction of Main Dependent Variables}

Using the information on the primary diagnosis, we generate the following dependent variables: (a) The All cause admission rate by aggregating over the total numbers of admissions on a given day in a given county and normalizing per 100,000 population. On a given day we observe 59.77 hospital admissions per 100,000 population (see Appendix Table B1). ${ }^{6}$ However,

\footnotetext{
${ }^{4}$ This excludes military hospitals and hospitals in prisons.

${ }^{5}$ Between 2000 and 2008, Germany had up to 468 different counties. Mostly, due to mergers and reforms of the administrative boundaries, the number of counties varies across years.

${ }^{6}$ Note that German data protection laws prohibit us from reporting min. and max. values.
} 
the rate varies substantially at the daily county level and the standard deviation is 25.73 . Note that the county refers to the county of residence of the patient, i.e., we observe on a daily basis how many of each county's citizens are hospitalized per 100,000 population.

(b) By extracting the ICD-10 codes 100-199-diseases of the circulatory system - the variable Cardiovascular admission rate is calculated. Admissions due to cardiovascular diseases are the single most important subgroup of admissions-9.53 admissions per 100,000 population account for $16 \%$ of all admissions (Table B1).

(c) Extracting the codes 120 and 121, the variable Heart attack rate shows that, on a given day, 1.59 people per 100,000 population are hospitalized due to heart attacks.

(d) Finally, we make use of the indicators injury rate (V01-X59) as well as the respiratory (J00-J99), metabolic (E00-E90), neoplastic (C00-D48), and infectious admission rate (A00-B99). We also test for daily DST related changes in suicide attempts (T14) and drug overdosing (T40) per 1 million population.

\section{Measuring Daylight Saving Time in Germany}

In Germany, clocks are set back and forth on the same day in all German counties. Table 2 shows that Germans spring forward at the last Sunday in March and fall back at the last Sunday in October. The day of the change in clocks is always the night from Saturday to Sunday from 2am to 3am and vice versa.

In total, 3,916 county-day observations mark the first day of summertime in our data (on average 435 county-day observations over 9 years). Analogously, 3,916 county-day observations mark the last day of summertime. 


\section{Empirical Specification}

\subsection{First Empirical Model: Extracting 15 Daily Effects ("Daily Approach")}

The first empirical specification estimates the following model by OLS: ${ }^{7}$

$$
\begin{aligned}
y_{c t}= & \beta_{0}+\beta_{1} \text { BeginDST }_{c t}+\beta_{2} \text { EndDST }_{c t}+\mathrm{X}_{c t}{ }^{\prime} \gamma+\text { Easter }_{c t}+\text { Vacation }_{c t} \\
& +\phi_{m} \delta_{y}+\operatorname{DOW}_{t} \phi_{m}+t+t^{2}+\mu_{c}+\varepsilon_{c t}
\end{aligned}
$$

where $y_{c t}$ stands for one BRFSS (German Hospital Census) health outcome variable for individual (county) $c$ on day $t$. BeginDST $T_{c t}$ is a vector of 15 daily binary variables $-7, \ldots . .,-1,0$, $1, \ldots ., 7$ indicating the seven days leading up to spring DST, the day of DST, and seven days following it. The variable EndDST $c$ is similarly constructed with daily dummies for the two weeks around fall DST.

For the German Census data, $\mathrm{X}_{c t}$ includes a series of county-specific control variables that may vary at the daily level, such as the share of admitted people in each age group, their gender, and the share of hospitals that are private. In addition, $\mathrm{X}_{c t}$ incorporates a series of county control variables that vary at the annual level, such as the unemployment rate or GDP per capita (see Appendix B). For the BRFSS, $X_{c t}$ measures a set of socio-demographic variables including age, sex, race, marital status, level of education, and employment status (see Appendix A).

Next, Easter ${ }_{c t}$ represents a vector of four Easter dummies indicating Holy Thursday, Good Friday, Easter Sunday and Easter Monday. For example, in 2005 and 2001, spring DST fell on Easter Sunday in Germany, and in 2008, the Sunday before spring DST was Easter Sunday. In Germany, Good Friday and Easter Monday are national holidays and admissions sharply drop on such days, which is why it is important to consider these religious holidays.

\footnotetext{
${ }^{7}$ The results are robust to running probit models and reporting marginal effects for the BRFSS when we employ binary outcome variables.
} 
Vacation $_{c t}$ indicates those days around spring and fall DST that are official school vacation days in Germany or the US. In Germany, official school vacations vary at the level of the 16 states by date and also in lengths. In spring, they are typically scheduled around Easter but could vary from early March until the end of April. They also vary in length from one up to three weeks, depending on the state. German fall vacations lie between the beginning of October and mid-November, and vary likewise by state, both in term of time and length. In the US, we also include a dummy for Halloween, which occurs on October $31^{\text {st }}$ each year. ${ }^{8}$

$D O W_{t}$ carries six binary variables netting out persistent day-of-week effects in hospital admissions or subjective health assessments. For example, relative to Sundays, hospital admissions increase by a staggering 52 per 100,000 pop. (mean: 59.57) on Mondays. Over the rest of the week, the relative increase decreases almost linearly to 37 admissions on Wednesdays and 12 admissions (per 100,000 population) on Fridays. Self-reported health also varies significantly by day-of-week; for example, $20.8 \%$ of survey respondents report "excellent health" on a Sunday, significantly higher than 19.0 on Mondays. Since it is imaginable that dayof-week health effects differ by season, we include a set of $D O W_{t} \phi_{m}$ interaction terms between the six day-of-week dummies and the 11 monthly dummies $\phi_{m}$. We also include month-year fixed effects $\phi_{m} \delta_{y}$, plus a linear and quadratic time trend $t+t^{2}$.

Lastly, when we use the Hospital Census we consider county fixed effects $\mu_{c}$, and when we use the BRFSS we consider state fixed effects. Since it is not likely that the county-day hospital admission rates are either independent over time or across space, we also correct the standard errors $\varepsilon_{c t}$ by applying two-way clustering across counties and over time (Cameron et al., 2011). When using the independently drawn and representative observations of the BRFSS, we cluster standard errors at the date level. All BRFSS regressions are probability weighted.

\footnotetext{
${ }^{8}$ Halloween is only a very recent phenomenon in Germany and has no tradition. However, the German findings are robust to including Halloween fixed effects.
} 


\subsection{Second Empirical Model: Assessing the Aggregated Week Effects ("Weekly Approach")}

The second empirical specification estimates an almost identical model:

$$
\begin{aligned}
y_{c t}= & \beta_{0}+\beta_{1} \text { WeekBeginDST }_{c t}+\beta_{2} \text { WeekEndDST }_{c t}+\mathrm{X}_{c t}{ }^{\prime} \gamma+\text { Easter }_{c t}+\text { Vacation }_{c t} \\
& +\phi_{m} \delta_{y}+\text { DOW }_{t} \phi_{m}+t+t^{2}+\mu_{c}+\varepsilon_{c t}
\end{aligned}
$$

However, instead of netting out systematic differences on a daily basis in the week before and after the DST change, we now employ WeekBeginDST $T_{c t}$ and WeekEndDST $T_{c t}$ as the main regressors of interest. WeekBeginDST $T_{c t}$ and WeekEndDST $T_{c t}$ are indicators for any of the seven days following the clock change, starting with the DST Sunday and ending on the next Saturday. This is basically a model where we aggregate effects at the weekly level and estimate the net health effects of DST over the entire following week.

\subsection{Identification}

The two empirical models above make use of an extremely saturated specification that is only estimable thanks to our rich databases while still yielding remarkably precise estimates.

The key idea is, however, that the running variable represents time and the treatment is represented by the specific DST dates. Time is arguably exogenous to individuals since humans cannot influence time. This can be thought of as a variant of an RD approach with time as the running variable. However, the specification is even richer since we do not just rely on the days before and after the treatment, i.e., DST, and compare the health of individuals before DST change to the health of individuals after DST change. In our main model of choice, in addition to the week before and after the DST change, we rely on four additional weeks as control groups: two more weeks before the two DST weeks of interest and two more weeks after the two DST weeks of interest. This means that we extract 6 weeks around spring DST as well as 6 weeks around fall DST to estimate our main models. Using the BRFSS, we do this for 10 years, i.e., exploit $10 * 6 * 6=360$ weeks or 2,520 days. The sample is corrected for the battery of sociodemographic and economic covariates discussed, in addition to county or state fixed effects, month-year as well as DOW-month fixed effects. Moreover, in robustness checks we show that 
the results are robust to including all 52 weeks of the year, not just the $2 * 6$ weeks around DST. Figure 1 illustrates the sample selection for the main model.

\section{[Insert Figure 1 about here]}

Table A3 in Appendix A compares the mean covariate values for the week of spring or fall DST, i.e., our "treatment week", to the control weeks prior and post the DST week. As seen, the mean values are very similar. The normalized difference proposed by Imbens and Wooldridge (2009) shows that no single value is above the critical sensitivity value of 0.25 and all are very close to zero in size. Also when comparing the treatment week mean values to the values of all other weeks of the year, not just the ones around DST, we find surprisingly balanced samples. This suggests that the BRFSS does a good job providing balanced samples over the 52 weeks of a year. Figures $A 1$ and $A 2$ likewise reinforce this point. Figure A2 shows that the BRFSS is very balanced in terms of sample sizes over the 12 calendar months of a year, and Figure A1 only shows a slight overall increase in the sample size of the ten years under consideration. The latter observation basically just means that the behavioral reactions in more recent years get attached slightly larger weights, which is no threat to our identification strategy. Recall that the length of the summer time was extended in 2007 (Table 1), which is exactly the year when the BRFSS reached its current steady state sample size.

Inspecting the observable characteristics of respondents on the DST Sundays in spring and fall yields no evidence that respondents systematically react to DST by being more or less likely to participate in the BRFSS (detailed results available upon request).

\section{Do the Dependent Variables Measure True Population Health Effects?}

One may wonder whether our health outcome variables measure true population health effects. In general, we would like to emphasize that both types of health measures-selfreported health in surveys as well as hospital admissions-are routinely used by health economists as their main health measures. This does not mean that they are flawless, but we believe that our findings are based on a broad enough set of different health measures from different countries to validate our findings. 
First, with respect to self-reported health: a rich health economics literature investigates reporting heterogeneity (or systematic reporting biases) in the standard self-assessed health (SAH) measure. One can summarize this literature as: (a) Despite its simplicity, it has been shown that SAH is an excellent predictor of true health (cf. McGee et al., 1999). (b) It has been demonstrated that responses to the general SAH question are systematically biased with respect to health and gender, whereas there is less evidence that this holds for other sociodemographics (cf. Ziebarth, 2010). For example, this means that older people tend to judge their health more mildly relative to younger ones on this absolute scale. People seem to refer to an age-gender dependent reference group when answering the question. Cross-country reporting biases due to language are another issue discussed in the literature (cf. Jürges, 2007). (c) Since we control for a rich set of socio-demographics and only rely on within country variations, age-gender dependent reporting heterogeneity should not be a threat to our estimates. (d) There is no reason to believe that the age or gender dependent bias is correlated with DST. (e) As shown in Table A3, the respondents' socio-demographics are very balanced in the weeks before and after the DST change.

Second, with respect to the German Hospital Admission Census: German geography, combined with the institutional setting of the German health care system, makes it very reasonable to assume that variations in hospitalizations represent variations in severe population health shocks. Germany has 82 million residents living in an area which has roughly the size of the US state Montana. Thus, the average German population density is about seven times as high as the US population density (231 vs. 32 people per $\mathrm{km}^{2}$ ) (U.S. Census Bureau, 2012; German Federal Statistical Office, 2012). The hospital bed density is also much higher. Per 100,000 population, Germany's health care infrastructure offers 824 hospital beds, while the US has only 304 (OECD, 2014). This illustrates that geographic hospital access barriers, such as travel distances, are low in Germany and significantly lower than in the US. Moreover, the uninsurance rate in Germany is below $0.5 \%$. The public health care system covers $90 \%$ of the population and copayment rates in the public scheme are uniform and low. The overwhelming majority of hospitals can be accessed independently of insurance status and provider networks 
are basically unknown in Germany. Thus, insurance barriers to hospital access are very low in Germany, and certainly lower than in the US.

\section{Results}

\subsection{Evidence from the BRFSS and the US: 2001-2010}

\section{Daily Approach}

Figures 2 and 3 plot the 15 daily dummy variables around spring and fall DST from the regression model in equation (1). Figure 1 focuses on the share of respondents who self-report that they are in excellent health, and Figure 2 shows the share of respondents reporting fair or poor health. All point estimates are plotted along with $90 \%$ confidence intervals.

\section{[Insert Figures 2 and 3 about here]}

Let us first focus on the time around spring DST in Figures 2a and 3a. As seen, there is no evidence of any systematic shift in self-assessed health before or after spring DST. Note that the standard errors are very tight, and that we employ a very rich fixed effects specification. For example, relative to the baseline share of Americans in excellent health (19\%, Table A2), with 95\% statistical certainty, this share does not decrease by more than 1ppt after the clocks are set forth by one hour in spring. Likewise, we can exclude with great statistical certainty that the share of Americans in fair or poor self-assessed health increases by more than 1.6ppt from a baseline of $18 \%$ (Figure $3 a$ and Table A1).

Next, we investigate the self-reported health effects of the fall DST. Figures $2 b$ and $3 b$ again plot the 15 daily coefficients of equation (1) around fall DST for the years 2001 to 2010. The dependent variables are again the share of Americans in excellent and fair/poor health. Figure

$3 \mathrm{~b}$ shows that there is no evidence that the share of respondents in bad health changes by more than +/- 2 ppt when the clocks are set back by one hour at the beginning of November.

However, Figure 2b provides some evidence that after "gaining" one hour in fall, the share of people who report excellent health increases by a statistically significant 1ppt on Monday, 
and persists until Thursday before the effect dissipates. The size of the probability-weighted coefficient is relatively small, but would translate into about 2.5 million marginal Americans who would report excellent instead of very good health after fall DST for four days.

The finding of a slight rightwards shift of the right tail of the subjective health distribution is reinforced by Figure $A 3 b$ in Appendix $A$. Figures $A 3$ and $A 4$ show the same pattern as above when the underlying model makes use of the full sample-i.e. all 52 weeks of the year instead of the $2 * 6$ weeks in the main specifications-and does not weight the regressions. As seen, the increase in health in Figure $\mathrm{A} 3 \mathrm{~b}$ also lasts for about four days before it disappears again. Moreover, Figures A3 and A4 also confirm that there is no evidence that spring DST has any systematic impact on self-assessed health. All pattern also remain robust when we explore movements from SAH category three (good health) to category two (very good health) or movements between categories one (poor health) and two (fair health). We find that the share of respondents in very good or excellent health increases by up to $1 \mathrm{ppt}$ on from 51 to $52 \%$ but there is no evidence that the share of respondents in poor health changes post DST (detailed results available upon request).

\section{Weekly Approach}

Next, we run equation (2), aggregate the effects up to the weekly level, and report the results in Table 3. Here we include the rich set of covariates stepwise to unravel their relative contribution to the estimated effects in size, sign, and significance. This exercise also simulates the more parsimonious approach of many existing studies. In particular studies in the medical and public health literature typically very sparsely control for seasonal confounders and focus on spring DST. Those studies often report statistically significant negative health effects of the spring DST change-findings that have been enthusiastically picked up by the media around the world.

\section{[Insert Table 3 about here]}

Columns (1) to (4) of Table 3 use excellent health as dependent variable and columns (5) to (8) fair or poor health. As usual, each column represents one separate model of which we 
report the relevant coefficient estimates Week of Begin/End DST. The most parsimonious models in columns (1) and (5) solely net out day-of-week (DOW), month, year, and state fixed effects. As seen, this results in positive coefficient estimates of 0.007 for bad health in column (5). Week of Begin DST is significant at the $5 \%$ level, which implies an increase in the share of respondents in bad health by $0.7 p p t$ on the week of spring DST. Similarly, the Week of End DST estimate is also positive and statistically significant, suggesting that time change in fall increases the share of people reporting poor or fair health by about $0.7 p p t$. In contrast, the estimates in column (1) using excellent health as dependent variable are negative but not statistically significant.

Adding month-year fixed effects, DOW-month fixed effects, as well as Easter, Halloween, and vacation controls in columns (2) and (6) barely alters the coefficient estimates. Still, one would find that both spring and fall DST increase the number of respondents in poor health by a small but precisely estimated share. However, further adding linear and quadratic time trends cuts the already small coefficient sizes further in half, and they become insignificant. In line with our daily approach illustrated in Figures 2 and 3, the preferred and fully saturated model specifications in columns (4) and (8) carry very small effect sizes and are statistically not significantly different from zero. Particularly the point estimates for the poor or fair health models are tiny: 0.0007 and -0.0005 for spring and fall DST, respectively.

\section{Robustness Checks}

Figures A3 and A4 already provided robustness checks for the daily approach by using the full sample. In addition, we varied the SAH cut-offs. Table A4 carries out the same alternations

using the weekly approach. As seen, all coefficient estimates are very small in size, precisely estimated but not statistically different from zero.

\section{Alternative Outcome Measures: Physical and Mental Health, Rest, and Sleep}

Table A5 in the Appendix makes use of alternative outcome measures and explores whether the self-reported number of days with (a) poor physical health, (b) poor mental health, or (c) insufficient rest changes after the clock changes in spring and fall. 
Note that the questions refer to the last 30 days, which may introduce measurement error and a non-straightforward interpretation. First of all, assume that there was no recall bias or measurement error and everybody would provide accurate answers. Further assume that DST would affect respondents for four days. Then, those who were interviewed on the day of DST change would report $X+/-1$ instead of $X$ days in poor health, those interviewed on Monday $X+/-2$ instead of $X$ days, and so on. Since our standard approach assigns respondents in weeks $t+2$ and $t+3$ the control group status (Figure 1), our estimates would be biased downwards since their retrospective 30 -day responses would be affected by DST as well. Therefore, in Table A5, we assign respondents interviewed in weeks $t+2$ and $t+3$ to the treatment group. However, in practice, we expect recall biases and that respondents weigh days closer to the interview day much stronger.

The findings again confirm the previous findings: the six Week of Begin DST and the six End of DST coefficients are all small in size and not statistically significant. For example, the coefficient estimate for \# days in past 30 days w/ poor mental health in column (3) has a size of $0.7 \%$ of the mean, and we can exclude with $95 \%$ statistical certainty that spring DST increases the number of days in bad mental health by more than 0.15 .

However, for \# days in past 30 days $w /$ insufficient rest we find suggestive evidence for small potential effects, both in spring and fall. The coefficient estimates are relatively large in spring, $2.5 \%$ of the mean, and also marginally statistically significant when we do not weight the regressions.

The latter findings is further reinforced in Table A6 where we use three BRFSS sleep measures as outcomes. In 2009, six states began to include questions about sleep inadequacy in the BRFSS, and this expanded to nine states in $2010 .{ }^{9}$ Column (1) uses \#Hours of Sleep. While the Week of Begin DST estimate is small and insignificant, the End of DST estimate has a size of $1.4 \%$ of the mean and is statistically significant at the $10 \%$ level. This suggests that a small group

\footnotetext{
${ }^{9}$ The six states are: Georgia, Hawaii, Illinois, Louisiana, Minnesota, and Wyoming. The nine states are: Arkansas, Connecticut, Delaware, District of Columbia, Hawaii, Minnesota, Missouri, Nevada, and Oregon.
} 
of presumably sleep deprived Americans get more sleep when one hour is "gained" during the night. A similar finding is provided in column (2) which measures tiredness during the day. The binary outcome Unintentionally falling asleep is one if this had happened at least once in the past 30 days. While the spring DST estimate is positive and carries no significance, the fall DST estimate is large in size (13\%) and statistically significant at the $5 \%$ level, suggesting that the share if Americans who unintentionally fall asleep during the day decreases by more than 4ppt in the week after fall DST change. Figure A5 documents this effect graphically using our daily approach and the plotted coefficients of equation (1). Despite some fluctuations due to the smaller sample size in this model, the four day effect following fall DST that we already observed in Figures $A 2 b$ and $A 3 b$ is easy to depict.

\subsection{Evidence from Administrative Hospitalization Data and Germany: 2000-2008}

Next, we use the same empirical approaches as above but study whether hospital admissions vary significantly in the days following DST, as is regularly claimed by the media and scientific publications in public health or medicine. As discussed, it is very likely that the variation in hospital admissions in Germany reflects true variation in underlying health shocks. The reasons are that (i) Germany has a very high population and hospital density. The distances to the next hospital are typically short and geographic access barriers low. (ii) Insurance access barriers are also low due to universal coverage, free choice of hospitals and small cost-sharing amounts.

Also recall that studying hospital admissions is an important complement to evaluating broader and milder population health effects using survey data. If DST would affect a small subgroup of citizens severely such that they would need to get hospitalized, survey data would miss these effects entirely since (a) very few survey respondents get hospitalized on a daily basis (about $5 \%$ of the total population on an annual basis), and (b) hospitalized people typically cannot respond to surveys.

\section{Daily Approach}

Figures 4 and 5 summarize the findings from the daily approach and plot the 15 coefficient estimates of equation (1). Figure 4 plots the impact on total admissions per 100,000 population 
(mean 59.8) and Figure 5 the impact on cardiovascular admissions per 100,000 population (mean 9.5). Despite conservative two-way clustering on the date and county level, the universe of all hospital admissions allow us to assess daily effects in a remarkably precise manner.

Figures $4 \mathrm{a}$ and $5 \mathrm{a}$ demonstrate that there is not much evidence for significant and severe negative health shocks after spring DST. The curves fluctuate slightly, which is not surprising, given the powerful data, but overall, they are remarkably flat around the zero line. This is confirmed and reinforced by Figures B1a to B9a in the Appendix that show the same flat graphs for the full sample, heart attacks, respiratory, metabolic, neoplastic and infectious admissions. The graphs also show that there is no evidence that - at any time in the week following DST change in spring whatsoever-injuries, suicide attempts or drug overdosing increases.

However, Figures $4 b$ and $5 b$ show an unambiguous clear pattern that resembles the BRFSS survey data pattern for the US and fall DST (see Figures $2 b, A 3 b$, and A5b): we observe a strong and distinct decrease in overall admissions as well as cardiovascular admissions on days one to four after the fall DST change. The effect is most pronounced on the Monday after the clocks are turned back by one hour, and then decreases smoothly over the next three days before they disappear on day five. The decrease for cardiovascular admissions equals about 1 admission per 100,000 population for four days, or about 40 admissions per 1 million residents over the entire week. In our set of robustness checks, in Figures B1b to B6b, one obtains exactly the same pattern using the full sample (Figure B1b), heart attacks (Figure B2b), injuries (Figure $\mathrm{B} 3 \mathrm{~b}$ ), respiratory and metabolic admissions (Figure B4b and B5b) as well as neoplastic admissions (Figure B6b). There is little room for interpretation whether these patterns could be due to voluntary behavioral responses when it comes, for example, to heart attacks. ${ }^{10}$

Some readers may become suspicious since the pattern look surprisingly similar across different disease categories. However, recall that the effects are identified by more than 3,916 fall DST county-day observations between 2000 and 2008 and different calendar dates, which

\footnotetext{
${ }^{10}$ Note that the German data do not allow us to distinguish between emergency room visits, elective visits and other type of admission. We solely see the primary diagnosis in the data and know that the patient stayed overnight, which excludes ambulatory elective surgeries.
} 
makes it extremely unlikely that systematic supply-side shocks produce these pattern. Also recall that these daily estimates are not nonparametric plots but stem from the rich fixed effects specification in equation (1). The daily effects plotted are net of vacation day and month-day-of-week (DOW) fixed effects as well as Easter effects. Moreover, the coefficients compare the relative admission rates for the 15 days plotted to the admission rates in the prior and post two weeks. Lastly, note that we identify exactly the same four-day pattern using American survey data (see Figures $2 b, A 3$ and $A 5$ ).

We interpret the similarity of these four-day pattern across different disease groups as strong support for our identification strategy. Moreover, the implication in terms of content would be that additional sleep is protective across a broad range of disease groups for people who are on the margin to getting admitted to a hospital. The medical advice for most people on the margin to getting admitted to a hospital is certainly to lay down and rest, which is essentially what one hour of additional sleep represents.

Note that the medical literature provides support of our notion that sleep matters and crucially affects patients in critical health conditions. For example, it is well know that cancer patients suffer from fatigue and sleep disorders that is "not well defined or well understood at present (Ancoli-Israel et al., 2002). Stepanski and Burgess (2007) note that "patients with cancer commonly report disturbed sleep, fatigue [...]" and that the overall significance of poor sleep as it relates to fatigue, pain, depression, or other health outcomes would be unknown. Furthermore, they state that the evaluation and treatment of sleep disturbance in patients undergoing treatment for cancer was important.

At first sight, for readers unfamiliar with this cancer-sleep phenomenon, the fall DST decrease in neoplastic admissions may appear strange and even seen as evidence contrary to our identification strategy. Knowing the above medical facts and considering that the ICD-10 coding solely refers to the main diagnosis of a patient with an overnight stay-and not the first time the disease is diagnosed-the significant decrease in neoplastic admissions by 1 per 100,000 pop. (-15\%) for four days actually reinforces that we identify true fall DST effects here. And that fall DST effects basically indicate the health effects of more sleep. 


\section{Placebo Daily Estimates}

When thinking about it carefully, ex ante, it is very difficult to identify severe health issues that require overnight stays in a hospital but are not, by construction, affected by more rest and sleep. We provide two approaches to placebo regressions. The first plots daily effects for health issues that are least likely to be affected by sleep, and the second approach (shown below) estimates weekly placebo DST effects for the weeks before and after the true DST changes.

First, Figures B7 to B9 plot the results of the daily approach for the diagnoses (i) suicide attempts, (ii) drug overdosing, and (iii) infectious diseases. While all three diagnoses could, in principle, be affected by sleep we consider it less likely in these cases, since (i) and (ii) should be driven by very time-persistent individual issues such as depression or addiction and not be triggered by one hour more or less sleep. Infectious diseases are transmitted airborne or through personal contact. Both ways of infection should, in principle, not be affected by DST. On the other hand, whether an admission is triggered may depend on the baseline health status of the infected person, which in turn, may be affected by DST.

The graphical evidence in Figures B7 to B9 shows very little evidence of a systematic reaction in either spring or fall DST. All curves are very flat around the zero line in the week following the change in clocks. If anything, one might observe the characteristic four-day decrease in admissions for infectious diseases. Overall, we interpret the fact that suicide attempts and drug overdosing do not react to DST as in line with our identification strategy and the identified four-day effects of the other disease groups.

\section{Weekly Approach}

As above, we summarize the results from the weekly approach in a table and just show the coefficients for Week of Begin/End DST. Again, each column of Table 4 represents one independent model and the outcome variable is displayed in the column header. 
First, in line with the findings from the US and the BRFSS, Table 4 does not provide much evidence for increases in hospitalization rates in general, or by specific disease groups, after springing forth one hour in spring. The coefficient estimates carry unsystematic positive or negative signs throughout and have a magnitude of about 1-2\% of the mean. Increases of 3-4\% can be excluded with 95\% statistical certainty (see also Figures 4a-5a, B1a-B8a). Two exceptions are the neoplastic admission rate which carries a coefficient size of $3.3 \%$ of the mean, is positive, and significant at the $5 \%$ level. Similar is the case for suicide attempts with a marginally significant, positive, and relatively large coefficient. Taken at face value, these estimates would suggest that one hour less sleep in spring does matter for these subgroups which is not totally unreasonable. However, inspecting the according Figures B6a and B7a, one does not find a convincing systematic pattern that could drive the results. ${ }^{11}$ Hence, we interpret these effects very carefully and keep in mind how powerful our data are and that even small random shocks could lead to significant daily coefficient estimates.

\section{[Insert Table 4 about here]}

Second, the aggregated weekly effects following fall DST, however, are entirely in line with our graphical representation of the daily approach: for all disease groups except drug overdosing, one finds significant decreases in admissions rates when falling back with the time in fall by one hour. Note that the coefficient estimates displayed show the average daily decrease in the week following fall DST, i.e., from Sunday of fall DST to the following Saturday. The results are entirely consistent with Figures $4 b$ and $5 b$ as well as B2b to B9b. For example, Figure $5 b$ shows significant decreases of heart admissions by about 1.2 per 100,000 between post-fall DST Monday and Thursday, i.e., about 5 fewer admissions in total. One also obtains exactly the same figure when multiplying the coefficient estimate of $-0.72 * * *$ by 7 days.

\footnotetext{
${ }^{11}$ For neoplasm, one finds significant increases in admissions on the Tuesday and Wednesday following spring DST change, but it is not obvious if this represents noise or true causality.
} 


\section{Placebo Weekly Estimates}

Our approach for placebo estimates using the weekly approach is as follows: We start in January of each year and select a six-week window of data as illustrated in Figure 1. Then we run our standard weekly model as in equation (2) pretending that the fourth week was the spring DST week. Next, we move the six week window one week further into February and repeat the approach. We reiterate until week six of our selected sample hits the true DST week and continue with six week windows post spring DST until end of June. ${ }^{12}$ In total, as such, we obtain 22 spring placebo weekly DST estimates. We repeat the exercise in a similar fashion for fall DST until the end of the year and obtain 23 pseudo-fall DST estimates. The weekly coefficient estimates are plotted in Figures B10a and B10b along with the true spring and fall estimates (rightmost coefficients \#23 and \#24).

Figure B10a shows the following. First, our empirical approach is sophisticated enough to eliminate most seasonal confounders that may affect admissions. Except for one estimate in the first half of the year, in Figure B10a, all weekly coefficient estimates are close to the zero line, fluctuate very little, and lie between the boundaries of $-2 \mathrm{ppt}$ and $+2 \mathrm{ppt}$ (relative to a mean of 59.8). Second, only one estimate-pseudo spring DST estimate \#15-is an outlier and -4, representing a decrease in admissions of almost -7\%. Pseudo spring DST estimate \#15 represents calendar week 18 with the last days of April and first days of May. In Germany, May $1^{\text {st }}$ is Labor Day, a national holiday. Admissions typically decrease strongly on national holidays, e.g., by 54 (or 90\%) on Easter Monday and 24 on Good Friday. Since we do not specifically control for May $1^{\text {st }}$ in the specification, the weekly decrease by -4 could be entirely explained by a May $1^{\text {st }}$ decrease of 28 admissions. Third, the latter point illustrates the limitations of our pseudo DST approach using administrative data: to eliminate all admission shocks, we would need to net out every possible seasonal confounder such as national holidays, all vacations days, periods of regional festivities such as carnival, and also consider specific singular shocks that may have affected admissions. While we are confident to having comprehensively considered all confounders during the true six spring and fall DST weeks, this is not the case for

\footnotetext{
12 The true DST week is never included in these placebo six week samples.
} 
all remaining weeks of the year. When interpreting the placebo estimates, this fact simply has to be considered when interpreting the estimates. Fourth, considering these remarks, Figure B10a does not provide any evidence that the true DST weekly estimate is different from zero and an outlier in any sense.

Most of the points just discussed also hold for Figure B10b. All pseudo DST effects are very small and fluctuate only slightly around the zero line, and are very precisely estimated. The only clear outliers are the true fall DST estimate, and pseudo fall DST estimate \#15. Pseudo fall DST estimate \#15 represents week 41 of the calendar year, which is typically the second week of October. We do not have a perfect explanation for this outlier. It could simply be noise and related to weather effects-admissions decrease on sunny days and mid-October typically provides the last nice days of the year-or due to vacation effects. Even though we control for school vacations, Germans without kids typically go on fall vacation for one to two weeks in October. October $3^{\text {rd }}$ is a national holiday in Germany (German Reunification Day) and often leads to a "long" weekend. Many Germans take advantage of this long weekend and extend it for their fall vacation.

Since the only other relatively large and negative weekly hospitalization effect is the true fall DST effect, together with all the other empirical and graphical evidence, Figure 10Cb provides strong evidence that our approach identifies the true causal DST effect on hospital admissions.

\subsection{Potential Mechanisms}

Overall, this paper provides strong evidence that population health improves when adjusting the clock backward by one hour in fall, but we find at most very modest negative health effects in spring when the clock is set forward by an hour. One explanation for this asymmetry is that people react differently to spring and fall time changes, perhaps in ways consistent with the notion of loss aversion. Loss aversion refers to people's tendency to more strongly prefer avoiding losses than acquiring gains, which has been robustly demonstrated in the literature. ${ }^{13}$

\footnotetext{
${ }^{13}$ Examples of recent research include loss aversion in the context of labor supply of taxi drivers (Camerer et al., 1997), housing prices (Genesove and Mayer, 2001), putting behavior of professional golf players (Pope and
} 
Without prior adjustments, people lose one hour of sleep in spring and gain an hour of sleep in fall. A loss-averse individual would therefore react more strongly to the spring DST than to the fall DST, for instance by going to bed an hour earlier to ensure to get the same hours of sleep.

The biological sleep rhythm of humans and intuition might also provide an explanation for the asymmetric effects. Without behavioral adjustments, most people would sleep one hour less in the night from Sunday to Monday. However, to the extent that such behavior leads to tiredness on the Monday, most people would probably simply go to bed one hour earlier Sunday night, e.g., at 10pm instead of $11 \mathrm{pm}$. In fall, by contrast, people would feel relaxed and well-rested on Monday due to the extra hour of sleep. To the extent that those people do not fully adjust their bedtime to wintertime but keep on going to bed at summertime $11 \mathrm{pm}$, the sleep extension would even carry over to the next days.

Another explanation for asymmetric behavioral sleep adjustments could be media exposure. In regular intervals, every year at spring and fall DST, the media broadly covers the topic. In particular when springing forward one hour, experts warn about the dramatic health dangers that DST could trigger. One consequence of this broad media exposure on negative health effects, such as heart attacks, could be that people on the margin are effective in adjusting their bedtime and/or act more carefully on the days following spring DST. Figure 6 shows that result of a google search request using the keywords "daylight savings time" and "heart attack". As seen, searches for DST spike at exactly the times of spring and fall DST. More interestingly, however, "heart attack" searches also seem to spike around spring DST but trend smoothly around fall DST, which yields support of hypothesis just discussed.

\section{[Insert Figure 6 about here]}

While a rigorous study of mechanisms is beyond the scope of this paper, we provide evidence on sleep adjustments using the sleep-related survey questions of the BRFSS in Table A6. Column 1 shows that people sleep on average an additional 0.1 hours in the entire week of 
fall DST, i.e, in total 0.7 hours more. However, there is no evidence that people sleep fewer hours as a result of spring DST. This finding strongly suggests that people simply adjust their bedtime following spring DST but not necessarily following fall DST, as suggested by the explanations above. In addition, column (2) shows that share of American who unintentionally fell asleep during the day decreases by a significant 4.4ppt in the week of fall DST but remains insignificant in spring DST.

The analogous graphical representation with the plotted daily effects is in Figure A5. Again we observe that the characteristic drop in fall lasts for four days (Figure A5b). Interestingly, Figure A5a also provides some evidence that spring DST may actually increase the share of tried people on the Monday and Tuesday following spring DST by a significant 0.5 and $1 \mathrm{ppt}-$ probably since behavioral adjustments are only partial. This finding is in line with the relatively large, albeit impressively estimated, "sufficient rest" coefficients in columns (5) and (6) of Table A5.

\section{Investigating Mechanisms using Socio-Demographics}

As a next step, we make use of the socio-demographics in the BRFSS to investigate effect heterogeneity and provide further evidence for underlying mechanisms. One could hypothesize that the effects differ depending on how time and schedule-constrained people are. If someone has the possibility to adjust their bed and their wake-up times flexibly, one would expect the potential health effects to be smaller. The most constrained individuals with respect to their wake-up time are employees without flexible working schedules. This is also the societal subgroup among which we would expect to find most sleep deprived people.

\section{[Insert Table 5 about here]}

Technically, we investigate effect heterogeneity by interacting the Week of Begin/End DST variables of the weekly approach in equation (2) with the socio-demographics of interest. The results are in Table 5. Overall, the findings are in line with what we already found: the triple interaction terms are mostly non-significant and small in size. However, if there is a pattern to observe, then it is a pattern that confirms the hypothesis above, namely that subgroups which 
are likely to be time-constraint, sleep deprived, and inflexible in their daily schedules are more affected. There is some evidence that (i) the share of males in bad health significantly increases following spring DST (column (5)) and that (ii) the increase in the share of people in excellent health following fall DST is driven by people under 50 (column (2)).

\section{Investigating Mechanisms using Daily Variation in Weather and Pollution}

Lastly, we investigate effect heterogeneity by weather and pollution conditions using the German Hospital Census. As explained in Appendix B, we collect daily data from more than one thousand ambient German weather and pollution monitors and measure weather and pollution conditions in every German county on a daily basis from 2000 to 2008.

We hope to learn more about the underlying behavioral mechanisms through the stratification via ambient conditions. The underlying hypothesis here is that weather conditions determine how and where individuals spend their time. Furthermore, being active outside may provide more opportunities for dangerous and health shock prone activities when humans are sleep deprived. Since pollution has also been shown to have a direct effect on hospital admissions (Ziebarth et al., 2013), we expect pollution to operate in interaction with the DST effects.

The first four columns of Table B2 stratify the DST effects by (1) temperature, (2) rainfall, (3) sunshine, and (4) cloudiness. The "better" the weather conditions for outdoor activities-i.e., higher temperatures, more sunshine, less rainfall, and less cloudiness - the more admission rates increase in the week following spring DST. However, interestingly, they seem to have no impact on admissions following fall DST. This finding reinforces the notion that spring and DST effects are asymmetric due to behavioral adjustments in spring but not in fall. Obviously, spending time outdoors does not matter when sleep deprived individuals get more sleep in fall. However it does play a role in spring. This could either be the case because sleep deprived individuals spend more time outdoors in a more dangerous environment which leads to higher admission rates. Or it could be that sleep deprived individuals do not adjust their bedtime and 
go to bed earlier precisely because the opportunity costs are higher when the outdoor conditions are better.

Next, columns (5) to (8) of Table B2 show that admissions increase whenever pollution conditions worsen, independent of spring and fall DST. The fact that the effects are not asymmetric suggests, in line with the literature, that pollution is always bad for humans on the margin, and also that these people do not or cannot adapt to outdoor air pollution. On the other hand, it reinforces the behavioral explanation discussed above since it is very likely and has been shown that weather conditions determine where and how people spend their time (Gebhart and Noland, 2014).

\section{Discussion and Conclusion}

This research comprehensively studies the question whether DST truly affects population health, which is a common perception that is reinforced by the media and medical studies. The presumably adverse health effects of DST regulation lead to controversial debates among policymakers and society about whether abolishing DST regulation would be a welfare increasing policy.

We put forward several arguments to contribute to this debate: First of all, to comprehensively assess effects of DST, one needs to consider both time changes - the spring as well as the fall change. Second, to assess DST population health effects, it is crucial to exploit very rich representative and broad datasets over many years. Since DST happens only twice a year, and typically on Sundays around Eastern and fall vacation times, it is crucial to run rich econometric specifications that consider weekday effects in addition to general and specific seasonal confounders. Third, it seems important to differentiate between the daily effects immediately after the DST change and the aggregated effects at a higher timely dimension, e.g., the weekly level. For example, it is likely that especially unhealthy people react to the broad media exposure in spring and adjust their behavior and act more carefully. While the DST change itself is exogenous, it is important to acknowledge that people may adjust their behavior as a reaction to it. Studying daily effects may help to pinpoint such behavior and also 
assess how long potential effects last. Differentiating daily from weekly effects is only feasible with very rich and powerful data. When researchers exploit energy, crime, fatality or hospitalization data they should also consider that these outcomes mechanically decrease since the spring DST Sunday only counts 23 instead of 24 hours.

This paper uses up to 3 million US survey respondents and all 160 million German hospital admissions over one decade to study the population health effects of DST. While the US BRFSS survey comprehensively captures subjective self-reported milder health conditions, the universe of hospital admissions captures severe health shocks. Our empirical models are based on a battery on robustness checks and yield surprisingly consistent results for the US and Germany.

Overall, contrary to many medical studies that are based on simpler identification strategies, we find very little evidence that spring DST has a broad and significant impact on population health. There is some minor evidence for sleep deprivation effects, but overall most people just seem to go to bed one hour earlier on Sunday evening after springing forward on Saturday night in spring. An alternative explanation is that, due to the broad media exposure, people simply act more carefully on the days following spring DST change. Recall that the spring change is regularly accompanied by media warnings on the potentially negative effects for the biorhythm. In any case, there is no evidence that hospital admissions increase or that a significant share of people would report more health issues.

In contrast, the fall DST change effectively means for many people-particularly sleep deprived and time-constraint people-that they can sleep one hour more. There exists broad and convincing evidence that millions of people in Western societies are heavily sleep deprived (Valdez et al. 1996; Duffy et al. 2001, Duffy and De Gennaro, 2001 ; Moore et. al., 2002; Roenneberg et al., 2007; Knutson et al., 2007). On the other hand, adverse health effects from sleep deprivation have been identified and are well documented in the medical literature (Pilcher and Huffcutt, 1996; Pilcher et al., 1997; Pilcher and Ott, 1998; Ferrara and De Gennaro, 2001; Ayas et al., 2003; Taheri et al., 2004; Mullington, et al., 2009). Our findings show consistent and robust evidence that health significantly improves for about four days following 
fall DST. About 2.5 million more Americans consider themselves in excellent health in selfreports, and one observes a decrease in the probability to fall asleep during the day. Moreover, the German Hospital Census clearly demonstrate a reduction in admissions in the days following fall DST. For example, cardiovascular admissions decrease by a significant 1 admission per 100,000 population over 4 days. We also find very similar pattern and decreases for other main diagnoses groups, but no reactions for suicide attempts or drug overdosing. These findings suggest that additional sleep can have significant health improvement and prevention effects for people on the margin to a severe health shock. This is one of the first clear quasiexperimental evidence for the health benefits of sufficient sleep. The immediate short-term medical advice for a person on the margin to getting a heart attack would certainly be to rest.

Finally, note that the main objective of this paper is to comprehensively evaluate the health effects of DST regulation in order to inform the ongoing debate. We abstain from drawing conclusions about the overall welfare effects of DST and its impact on other human behavior such as energy use or criminal behavior. We also would like to point to a caveat of this type of reduced-form empirical research: our approach is well-suited for the identification of causal and immediate intent-to-treat effects, but less suited to causally identify longer-term effects that may slowly accumulate over time. For example, it is imaginable that more or less daylight cumulatively and slowly affects human mood and depression rates over time. More research is necessary to assess all aspects of DST regulation.

\section{Literature}

Ayas, N. T.; White, D. P.; Al-Delaimy, W. K.; Manson, J. E.; Stampfer, M. J.; Speizer, F. E.; Patel, S.; Hu, F. B. (2003): "A Prospective Study of Self-Reported Sleep Duration and Incident Diabetes in Women," Diabetes Care, 26(2): 380-384.

Aldridge, A. O. (1956): „Franklin's Essay on Daylight Saving,” American Literature, 28(1): 23-29.

Alsousou, J.; Butler, D.; Bourma, O.; Lecky, F.; Willett, K. (2011): Daylight Saving Time (DST) Transition: the Effect on Serious or Fatal Road Traffic Collision Related Injuries, Journal of Bone \& Joint Surgery, British Volume, 94-B, SUPP II, 309

Ancoli-Israel, S.; Moore, P. J.; Jones, V. (2001): "The Relationship between Fatigue and Sleep in Cancer Patients: A Review, " European Journal of Cancer Care, 10(4): 245-255. 
Barnes, C. M.; Wagner, D. T. (2009): "Changing to Daylight Saving Time Cuts into Sleep and Increases Workplace Injuries," Journal of Applied Psychology, 94 (5): 1305-1317.

Berk, M.; Dodd, S.; Hallam, K.; Berk, L.; Gleeson, J.; Henry, M. (2008): "Small Shifts in Diurnal Rhythms are Associated with an Increase in Suicide: The Effect of Daylight saving," Sleep and Biological Rhythms, 6(1): 22-25

Bloomberg (2012): „Putin Complains Medvedev's End of Winter Time Creates 'Problems'," December 20, 2012, http://www.bloomberg.com/news/2012-12-20/putin-complainsmedvedev-s-end-of-winter-time-creates-problems-.html

Brahmana, R. K.; Hooy, C.-W.; Ahmad, Z. (2012): "Psychological Factors on Irrational Financial Decision Making: Case of Day-of-the Week Anomaly," Humanomics: The International Journal of Systems and Ethics, 28(4): 236-257.

Camerer, C; Babcock, L; Loewenstein, G; Thaler, R (1997): “Labor Supply of New York City Cabdrivers: One Day at a Time," Quarterly Journal of Economics, 112(2): 407-441.

Cameron, A. C.; Gelbach, J. B.; Miller, D. L. (2011): "Robust Inference With Multiway Clustering," Journal of Business \& Economic Statistics, 29(2): 238-249.

CDC (2014): Behavioral Risk Factor Surveillance System (BRFSS), Centers for Disease Control and Prevention, http://www.cdc.gov/brfss/, last retrieved on November 23, 2014.

Coren, S. (1996a): "Daylight Savings Time and Traffic Accidents," New England Journal of Medicine, 334(14): 924-925.

Coren, S. (1996b): “Accidental Death and the Shift to Daylight Savings Time," Perceptual and Motor Skills, 83(3): 921-922

Doleac, J. L. and Nicholas J. S. (2015): "Under the Cover of Darkness: How Ambient Light Influences Criminal Activity," Review of Economics and Statistics, forthcoming.

Duffy, J. F.; Rimmer, D. W.; Czeisler, C. A. (2001): "Association of Intrinsic Circadian Period With Morningness-Eveningness, Usual Wake Time, and Circadian Phase," Behavioral Neuroscience, 115(4), 895-899.

Duffy, M.; De Gennaro, L. (2001): “How Much Sleep Do We Need?" Sleep Medicine Reviews, 5(2): 155-179.

Ferguson, S. A.; Preusser, D. F.; Lund, A. K.; Zadorand, P. L.; Ulmer, R. G. (1995): “Daylight Saving Time and Motor Vehicle Crashes: the Reduction in Pedestrian and Vehicle Occupant Fatalities," American Journal of Public Health, 85(1): 92-95.

Ferrara, M.; De Gennaro, L. (2001): “How Much Sleep Do We Need?" Sleep Medicine Reviews, 5(2): $155-179$. 
Foerch, C.; Korf, H.-W.; Steinmetz, H.; Sitzer, M.; Arbeitsgruppe Schlaganfall Hessen (ASH) (2008): "Abrupt Shift of the Pattern of Diurnal Variation in Stroke Onset With Daylight Saving Time Transitions," Circulation, 118(3): 284-290.

Franklin, B., anonymously (1784). "Aux Auteurs du Journal," Journal de Paris (in French) (Duke University Press) 28 (117): 23. doi:10.2307/2922719. JSTOR 2922719. English version: http://www.webexhibits.org/daylightsaving/franklin3.html, accessed on November 9, 2013

Gaski, J. F.; Sagarin, J. (2011): "Detrimental Effects of Daylight-Saving Time on SAT Scores," Journal of Neuroscience, Psychology, and Economics, 4(1): 44-53.

Gebhart, K. and Noland, R. (2014): "The Impact of Weather Conditions on Bikeshare Trips in Washington, DC," Transportation, 41(6): 1205-1225.

Genesove, D.; Mayer, C. (2001): "Loss Aversion and Seller Behavior: Evidence from the Housing Market," Quarterly Journal of Economics, 116(4): 1233-1260.

German Federal Statistical Office (2012): Statistical Yearbook 2012 for the Federal Republic of Germany. Metzler-Poeschel.

Hamermesh, D. S.; Myers, C. K.; Pocock, M. L. (2008): “Cues for Timing and Coordination: Latitude, Letterman, and Longitude," Journal of Labor Economics, 26(2): 223-246.

Hanigan, I.; Hall, G. and Dear, K. B. G. (2006): "A Comparison of Methods for Calculating Population Exposure Estimates of Daily Weather for Health Research," International Journal of Health Geographics, 38(5): 1.

Hicks, G. J.; Davis, J., W.; Hicks, R. A. (1998): "Fatal Alcohol-Related Traffic Crashes Increase Subsequent to Changes to and from Daylight Savings Time," Perceptual and Motor Skills, 86(3): 879-882.

Homonoff, T. (2013) "Can Small Incentives Have Large Effects? The Impact of Taxes versus Bonuses on Disposable Bag Use" Princeton University, Working Paper 1483, Department of Economics.

Huang, A.; Levinson, D. (2010): "The Effects of Daylight Saving Time on Vehicle Crashes in Minnesota," Journal of Safety Research, 41(6): 513-520.

Imbens, G. W.; Wooldridge, J. M. (2009): "Recent Developments in the Econometrics of Program Evaluation," Journal of Economic Literature, 47(1): 5-86.

Janszky, I.; Ljung, R. (2008): "Shifts to and from Daylight Saving Time and Incidence of Myocardial Infarction," New England Journal of Medicine, 359(18): 1966-1968.

Janszky, I.; Ahnve, S.; Ljung, R.; Mukamal, K. J.; Gautam, S.; Wallentin, L.; Stenestrand, U. (2012): "Daylight Saving Time Shifts and Incidence of Acute Myocardial Infarction - Swedish Register of 
Information and Knowledge About Swedish Heart Intensive Care Admissions (RIKS-HIA), Sleep Medicine, 13(3): 237-242.

Jiddou, M. R.; Pica, M.; Boura, J.; Qu, L.; Franklin, B. A. (2013): "Incidence of Myocardial Infarction With Shifts to and From Daylight Savings Time," The American Journal of Cardiology, 111(5): 631-635.

Jürges, H. (2007): "True Health vs. Response Styles: Exploring Cross-Country Differences in SelfReported Health," Health Economics, 16(2), 163-178.

Kantermann, T.; Juda, M.; Merrow, M.; Roenneberg, T. (2007): "The Human Circadian Clock's Seasonal Adjustment Is Disrupted by Daylight Saving Time," Current Biology, 17(22): 1996-2000.

Kellogg, R.; Wolff, H. (2008): "Does Extending Daylight Saving Time Save Energy? Evidence from an Australian Experiment," Journal of Environmental Economics and Management 56: 207-220.

Knutson, K. L.; Spiegel, K.; Penev, P.; Van Cauter, E. (2007): "The Metabolic Consequences of Sleep Deprivation", 11(3): 163-178.

Kotchen, M. J.; Grant, L. E. (2011): "Does Daylight Saving Time Save Energy? Evidence from a Natural Experiment in Indiana," The Review of Economics and Statistics, 93(4): 1172-1185.

Kountouris, Y.; Remoundou, K. (2014): “About time: Daylight Saving Time Transition and Individual Well-Being," Economics Letters, 122(1): 100-103.

Kramer, L. A.; Kamstra, M. J.; Levi, M. D. (2000): "Losing Sleep at the Market: The Daylight Saving Anomaly," American Economic Review, 90(4): 1005-1011.

Kramer, L. A.; Kamstra, M. J.; Levi, M. D. (2002): "Losing Sleep at the Market: The Daylight Saving Anomaly: Reply," American Economic Review, 92(4): 1257-1263.

Krarti, M.; Hajiah, A. (2011): "Analysis of Impact of Daylight Time Savings on Energy Use of Buildings in Kuwait," Energy Policy, 39(5): 2319-2329.

Kuehnle, D.; Wunder, C. (2014): “Using the Life Satisfaction Approach to Value Daylight Savings Time Transitions: Evidence from Britain and Germany," BGPE WP 156.

Lahti, T.; Leppämäki, S.; Ojanen, S.-M.; Haukka, J.; Tuulio-Henriksson, A.; Lönnqvist, J.; Partonen, T. (2006): "Transition into Daylight Saving Time Influences the Fragmentation of the Rest-Activity Cycle," Journal of Circadian Rhythms, 4(1): 1-6.

Lahti, T.; Nysten, E.; Haukka, J.; Sulander, P.; Partonen, T. (2010): “Daylight Saving Time Transitions and Road Traffic Accidents," Journal of Environmental and Public Health. Article ID 657167. 
Lahti, T.; Sysi-Aho, J., Jari, H.; Partonen, T. (2011): “Work-Related Accidents and Daylight Saving Time in Finland," Occupational Medicine, 61(1): 26-28.

McGee, D. L., Liao, Y., Cao, G., Cooper, R. S. (1999): "Self-Reported Health Status and Mortality in a Multiethnic US Cohort," American Journal of Epidemiology, 149(1), 41-46.

Moore, P. J.; Adler, N. E.; Williams, D. R.; Jackson, J. S. (2002): "Socioeconomic Status and Health: The Role of Sleep," Psychosomatic Medicine, 64(2): 337-344.

Momani, M. A.; Yatim, B.; Ali, M. A. M. (2009): "The Impact of the Daylight Saving Time on Electricity Consumption--A Case Study from Jordan," Energy Policy, 37(5): 2042-2051.

Mullington, J. M.; Haack, M.; Toth, M.; Serrador, J. M.; Meier-Ewert, H. K. (2009): “Cardiovascular, Inflammatory, and Metabolic Consequences of Sleep Deprivation," Progress in Cardiovascular Diseases, 51(4): 294-302.

OECD (2014). OCED Health StatExtracts 2012. http://stats.oecd.org, last accessed on November 20, 2014.

Pilcher, J. J.; Huffcutt, A. J. (1996): "Effects of Sleep Deprivation on Performance: A MetaAnalysis," Sleep: Journal of Sleep Research \& Sleep Medicine, 19(4): 318-326.

Pilcher, J. J.; Ginter, D. R.; Sadowsky, B. (1997): “Sleep Quality Versus Sleep Quantity: Relationships Between Sleep and Measures of Health, Well-Being and Sleepiness in College Students," Journal of Psychosomatic Research, 42(6): 583-596.

Pilcher, J. J.; Ott, E. S. (1998): “The Relationships Between Sleep and Measures of Health and Weil-Being in College Students: A Repeated Measures Approach," Behavioral Medicine, 23(4): 170-178.

Pinegar, J. M. (2002): “Losing Sleep at the Market: Comment," American Economic Review, 92(4): 1251-1256.

Pope, D.; Schweitzer, M. (2010): "Is Tiger Woods Loss Averse? Persistent Bias in the Face of Experience, Competition, and High Stakes" American Economic Review, 101(1): 129-157.

Rees-Jones, A. (2014) "Loss Aversion Motivates Tax Sheltering: Evidence from US Tax Returns," mimeo.

Roenneberg, T.; Kuehnle, T.; Juda, M.; Kantermann, T.; Allebrandt, K.; Gordijn, M.; Merrow, M. (2007): “Epidemiology of the Human Circadian Clock," Sleep Medicine Reviews, 11(6): 429-438.

Sexton, A. L.; Beatty, T. K. M. (2014): "Behavioral Responses to Daylight Savings Time," Journal of Economic Behavior \& Organization, 107(PA): 290-307. 
Sood, N.; Ghosh, A. (2007): "The Short and Long Run Effects of Daylight Saving Time on Fatal Automobile Crashes," The B.E. Journal of Economic Analysis \& Policy, 7(1): 1-22.

Socio-Economic Panel (SOEP): Data for Years 1984-2011, Version 29, SOEP, 2011, doi: 10.5684/soep.v28.

Stepanski, E. J.; Burgess, H. J. (2007): “Sleep and Cancer," Sleep Medicine Clinics, 2(1): 67-75.

Taheri, S.; Lin, L.; Austin, D.; Young, T.; Mignot, E. (2004): “Short Sleep Duration Is Associated with Reduced Leptin, Elevated Ghrelin, and Increased Body Mass Index," PLoS Medicine, 1(3): e62.

U.S. Census Bureau (2012). US Census 2010. http://2010.census.gov/2010census/data, last accessed on November 20, 2014.

United States Environmental Protection Agency (EPA) (2005): "Summary of the Energy Policy Act 2005", http://www2.epa.gov/laws-regulations/summary-energy-policy-act, last accessed on October 24, 2013.

Valdez, P.; Ramírez, C.; García, A. (1996): “Delaying and Extending Sleep During Weekends: Sleep Recovery or Circadian Effect?" Chronobiology International, 13(3): 191-198.

Wagner, G. G., Frick, J. R., Schupp, J. (2007): "The German Socio-Economic Panel Study (SOEP) Evolution, Scope and Enhancements." Journal of Applied Social Science Studies (Schmollers Jahrbuch), 127(1): 139-169.

Wagner, D. T.; Barnes, C. M.; Lim, V. K. G.; Ferris, D. L. (2012): “Lost Sleep and Cyberloafing: Evidence from the Laboratory and a Daylight Saving Time Quasi Experiment, " Journal of Applied Psychology, 97(5): 1068-1076.

Witte, D. R. and Grobbee, D.E. and Bots, M.L. and Hoes, A.W. (2005): "A Meta-Analysis of Excess Cardiac Mortality on Monday, "European Journal of Epidemiology, 20(5): 401-406.

Ziebarth, N. R. (2010): "Measurement of Health, Health Inequality, and Reporting Heterogeneity, "Social Science \& Medicine, 71(1), 116-124.

Ziebarth, N. R., Schmitt, M. and Karlsson, M. (2013): "The Short-Term Short-Term Population Health Effects of Weather and Pollution," revised version based on IZA Discussion Papers 7875, available on www.nicolasziebarth.com. 
Figures and Tables

Figure 1: Sample Selection of Main Models-Extracting 6 Weeks around DST Change

Controls


Figure 2a and b: BRFSS Daily Approach:

Daily Effects of DST on Share of People Reporting Excellent Health, 2001-2010

\section{Excellent Health \\ Spring DST}

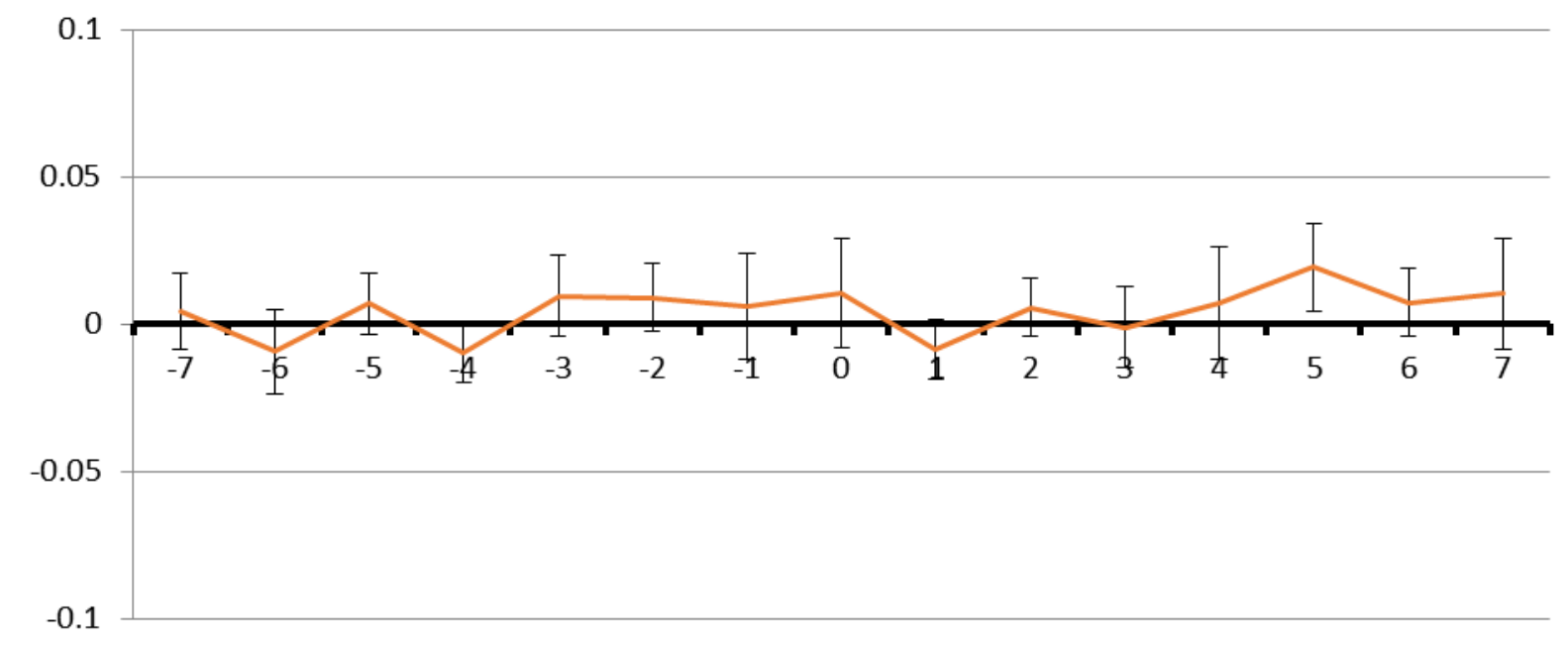

Excellent Health

Fall DST

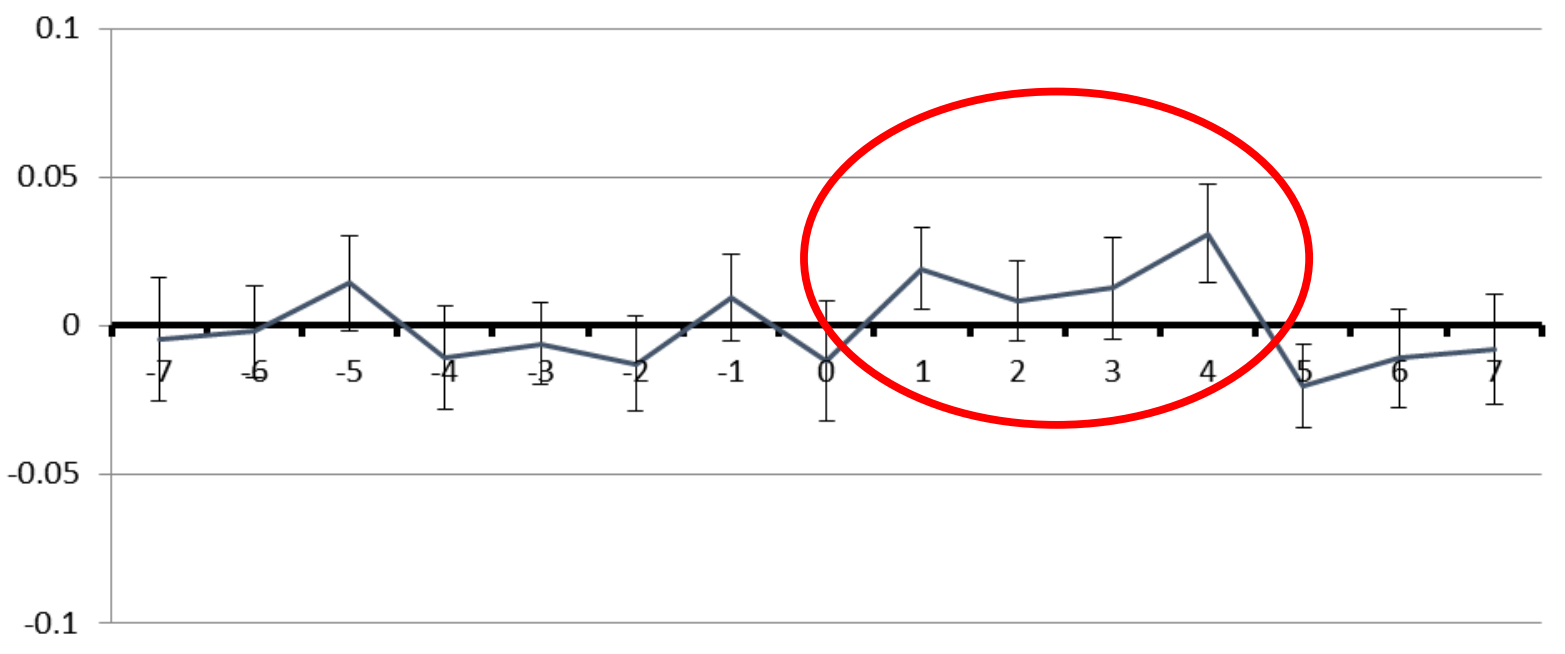


Figure 3a and b: BRFSS Daily Approach

Daily Effects of DST on Share of People Reporting Fair or Poor Health, 2001-2010

Fair or Poor Health

Spring DST

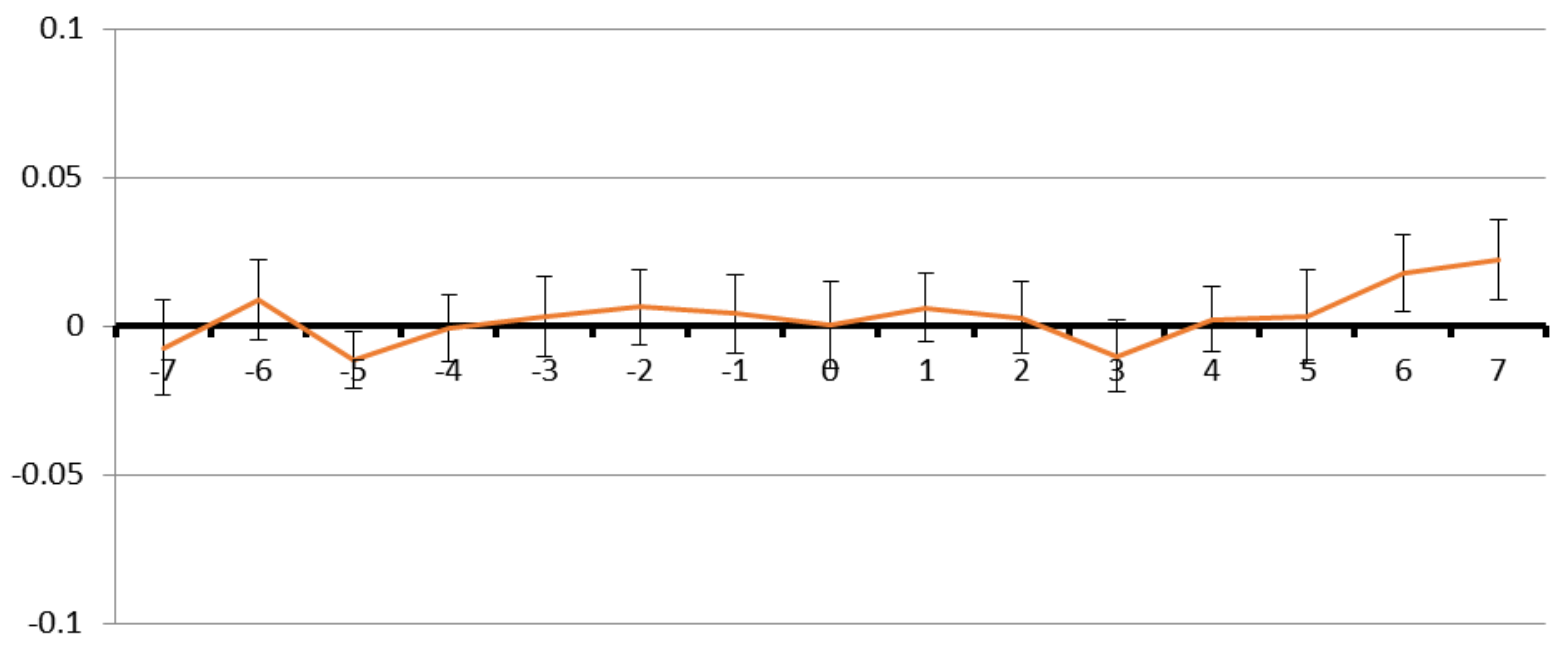

Fair or Poor Health

Fall DST

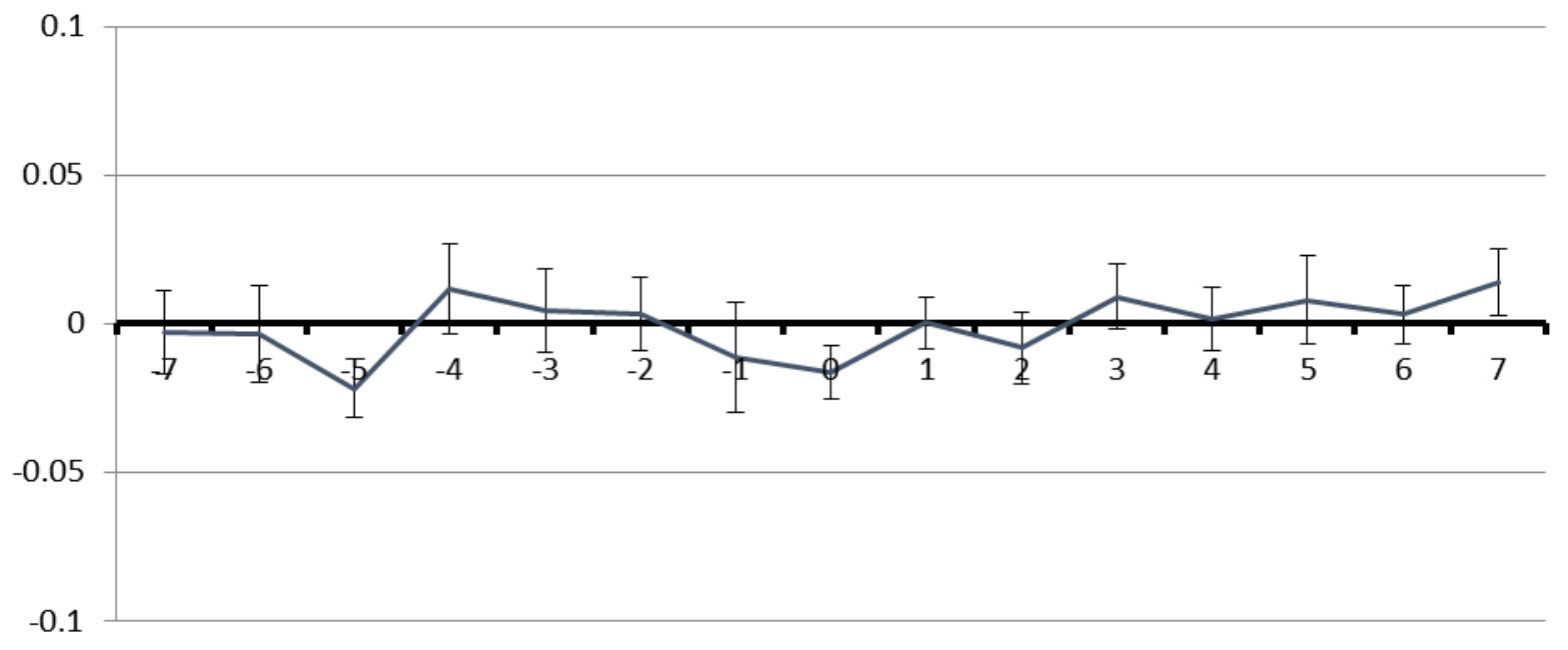


Figure 4a and b: Hospital Census Daily Approach

Daily Effects of DST on Total Hospital Admissions, 2000-2008

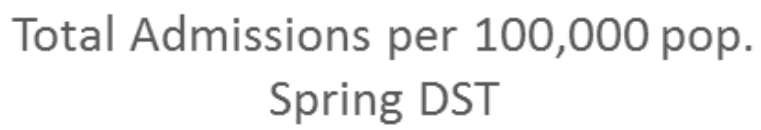

15

10

5

$-5$

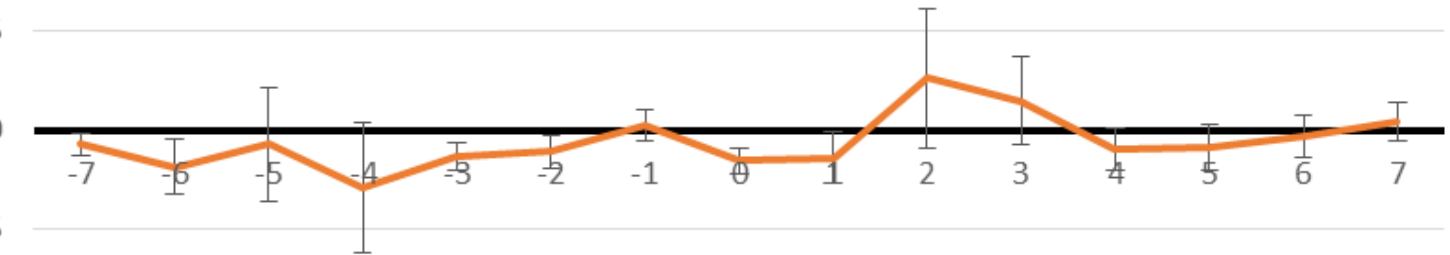

$-10$

$-15$

$-20$

Total Admissions per 100,000 pop.

Fall DST

15

10

5

0

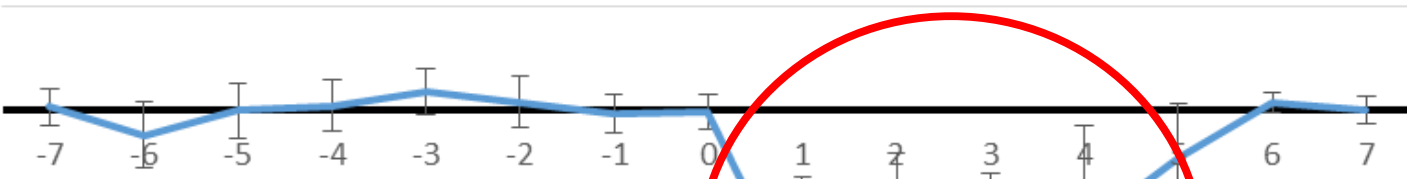

$-5$

$-10$

$-15$

$-20$

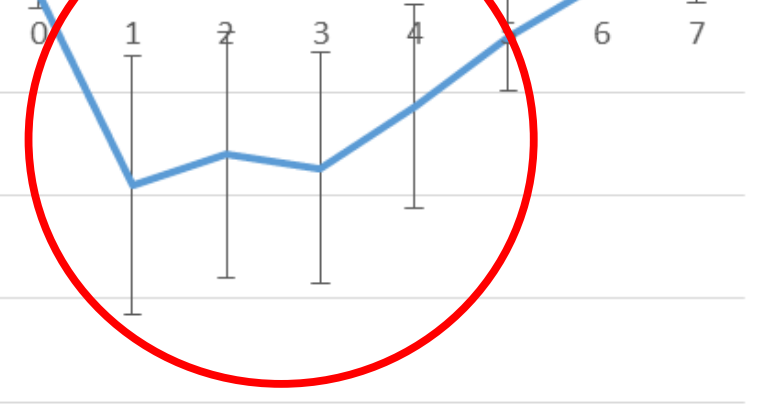


Figure 5a and b: Hospital Census Daily Approach

Daily Effects of DST on Cardiovascular Admissions, 2000-2008

\section{Cardiovascular Admissions per 100,000 pop. \\ Spring DST}

\section{2}

1.5

1

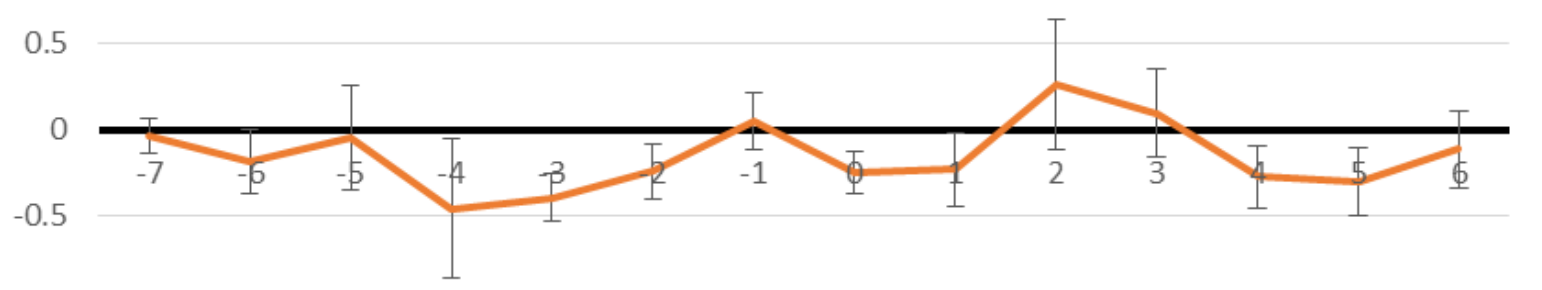

$-1$

$-1.5$

$-2$

\section{Cardiovascular Admissions per 100,000 pop.}

\section{Fall DST}

1

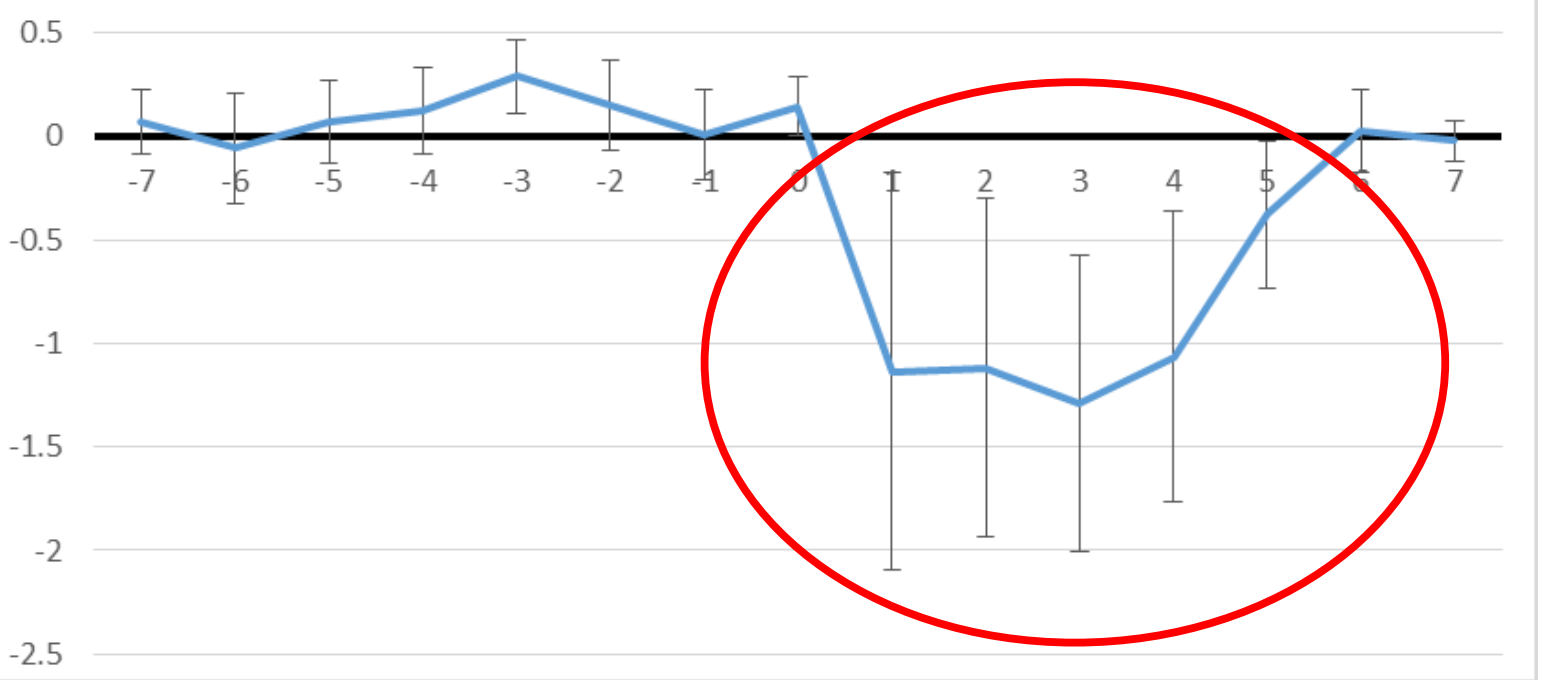


Figure 6: Google Searches

"DST" and "Heart Attack" Google Search Volume Over the Year

Compare Searchterms -

"daylight savings time"

heart attack

Search term

Search term

+ Add term

Interest over time

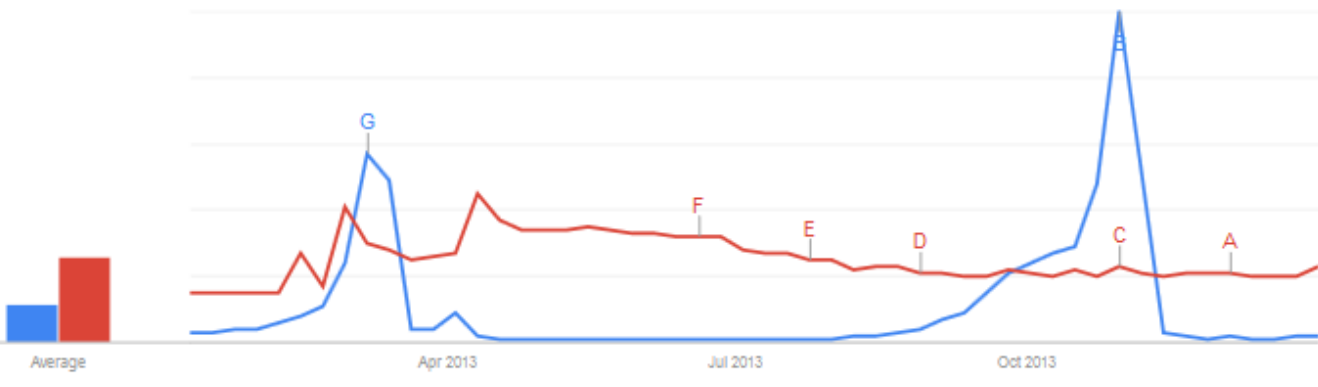

$\langle/\rangle$

Regional interest

"daylight savings t... heart attack

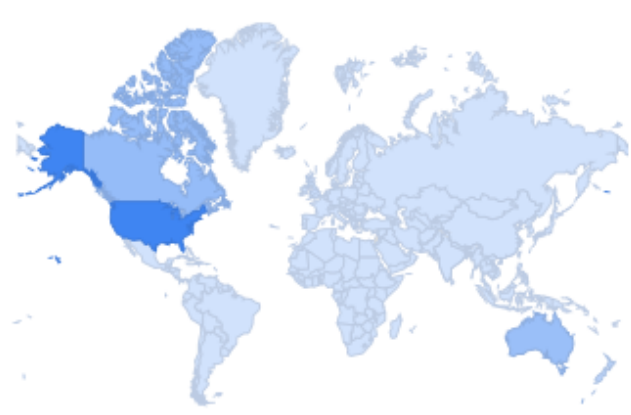

United States

Region | City

- View change over time

$\langle/\rangle$

$\langle/\rangle$ 
Table 1: DST US

Begin and End of Daylight Saving Time (DST) in the US (2001-2010)

\begin{tabular}{lcc}
\hline Year & DST spring & DST fall \\
\hline 2001 & $4 / 1 / 2001$ & $10 / 28 / 2001$ \\
2002 & $4 / 7 / 2002$ & $10 / 27 / 2002$ \\
2003 & $4 / 6 / 2003$ & $10 / 26 / 2003$ \\
2004 & $4 / 4 / 2004$ & $10 / 31 / 2004$ \\
2005 & $4 / 3 / 2005$ & $10 / 30 / 2005$ \\
2006 & $4 / 2 / 2006$ & $10 / 29 / 2006$ \\
\hline 2007 & $3 / 11 / 2007$ & $11 / 4 / 2007$ \\
2008 & $3 / 9 / 2008$ & $11 / 2 / 2008$ \\
2009 & $3 / 8 / 2009$ & $11 / 1 / 2009$ \\
2010 & $3 / 14 / 2010$ & $11 / 7 / 2010$ \\
\hline
\end{tabular}

Table 2: DST Germany

Begin and End of Daylight Saving Time (DST) in Germany (1999-2008)

\begin{tabular}{lcc}
\hline Year & DST spring & DST fall \\
\hline 2000 & $3 / 26 / 2000$ & $10 / 29 / 2000$ \\
2001 & $3 / 25 / 2001$ & $10 / 28 / 2001$ \\
2002 & $3 / 31 / 2002$ & $10 / 27 / 2002$ \\
2003 & $3 / 30 / 2003$ & $10 / 26 / 2003$ \\
2004 & $3 / 28 / 2004$ & $10 / 31 / 2004$ \\
2005 & $3 / 27 / 2005$ & $10 / 30 / 2005$ \\
2006 & $3 / 26 / 2006$ & $10 / 29 / 2006$ \\
2007 & $3 / 25 / 2007$ & $10 / 28 / 2007$ \\
2008 & $3 / 30 / 2008$ & $10 / 26 / 2008$ \\
\hline
\end{tabular}


Table 3: BRFSS Weekly Approach: Stepwise

Weekly Effects of Begin and End of DST on Self Assessed Health (SAH) 2001-2010: Adding Controls Stepwise

\begin{tabular}{|c|c|c|c|c|c|c|c|c|}
\hline & $\begin{array}{c}(1) \\
\text { Excellent } \\
\text { health }\end{array}$ & $\begin{array}{c}(2) \\
\text { Excellent } \\
\text { health }\end{array}$ & $\begin{array}{c}(3) \\
\text { Excellent } \\
\text { health }\end{array}$ & $\begin{array}{c}\text { (4) } \\
\text { Excellent } \\
\text { health }\end{array}$ & $\begin{array}{c}\text { (5) } \\
\text { Fair or Poor } \\
\text { health }\end{array}$ & $\begin{array}{c}\text { (6) } \\
\text { Fair or Poor } \\
\text { health }\end{array}$ & $\begin{array}{c}\text { (7) } \\
\text { Fair or Poor } \\
\text { health }\end{array}$ & $\begin{array}{c}\text { (8) } \\
\text { Fair or } \\
\text { Poor health }\end{array}$ \\
\hline $\begin{array}{l}\text { Week of Begin DST } \\
\text { (2am } \rightarrow \text { 3am in spring) }\end{array}$ & $\begin{array}{l}-0.00309 \\
(0.00357)\end{array}$ & $\begin{array}{l}-0.00191 \\
(0.00348)\end{array}$ & $\begin{array}{c}0.00068 \\
(0.00345)\end{array}$ & $\begin{array}{c}0.00312 \\
(0.00330)\end{array}$ & $\begin{array}{r}0.00735^{* *} \\
(0.00342)\end{array}$ & $\begin{array}{l}0.00623 * \\
(0.00357)\end{array}$ & $\begin{array}{c}0.00268 \\
(0.00347)\end{array}$ & $\begin{array}{c}0.00069 \\
(0.00296)\end{array}$ \\
\hline $\begin{array}{l}\text { Week of End DST } \\
(2 \mathrm{am} \rightarrow 1 \mathrm{am} \text { in fall) }\end{array}$ & $\begin{array}{l}-0.00029 \\
(0.00426)\end{array}$ & $\begin{array}{l}-0.00258 \\
(0.00423)\end{array}$ & $\begin{array}{c}0.00225 \\
(0.00432)\end{array}$ & $\begin{array}{c}0.00602 \\
(0.00424)\end{array}$ & $\begin{array}{c}0.00743 * * \\
(0.00345)\end{array}$ & $\begin{array}{c}0.01007 * * * \\
(0.00352)\end{array}$ & $\begin{array}{c}0.00446 \\
(0.00347)\end{array}$ & $\begin{array}{l}-0.00047 \\
(0.00294)\end{array}$ \\
\hline \multicolumn{9}{|l|}{ Controls } \\
\hline State FE & $x$ & $x$ & $\mathrm{X}$ & $X$ & $x$ & $x$ & $x$ & $\mathrm{x}$ \\
\hline Day of Week FE & $x$ & & & & $x$ & & & \\
\hline Month FE & $x$ & & & & $x$ & & & \\
\hline Year FE & $x$ & & & & $x$ & & & \\
\hline Easter and Halloween & & $x$ & $x$ & $x$ & & $x$ & $x$ & $x$ \\
\hline Day of Week * Month FE & & $x$ & $x$ & $x$ & & $x$ & $x$ & $x$ \\
\hline Month * Year FE & & $x$ & $x$ & $x$ & & $x$ & $x$ & $x$ \\
\hline Linear \& quadr. time trend & & & $x$ & $x$ & & & $x$ & $x$ \\
\hline Socioecon. covariates & & & & $x$ & & & & $x$ \\
\hline Mean of dep. Var. & 0.193 & 0.193 & 0.193 & 0.193 & 0.184 & 0.184 & 0.184 & 0.184 \\
\hline $\mathrm{R}^{2}$ & 0.0009 & 0.0039 & 0.0041 & 0.0643 & 0.0010 & 0.0088 & 0.0091 & 0.2040 \\
\hline Observations & 799,171 & 799,171 & 799,171 & 799,171 & 799,171 & 799,171 & 799,171 & 799,171 \\
\hline
\end{tabular}

Notes: Standard errors in parentheses are clustered at the date level. $* * *$ Significant at $1 \%$ level, $* * 5 \%, * 10 \%$. Regressions are probability-weighted. Begin/End DST are indicator variables equal to 1 if the interview is on the DST Sunday or one of the following 6 days. Excellent health is a binary variable measuring the 19.3 percent of BRFSS respondents who consider themselves as in excellent health. Fair or Poor health is a binary variable measuring the 18.4 percent of BRFSS respondents who consider themselves as in fair or poor health (see also Table A1). Each column is one model as in equation (2). 


\begin{tabular}{|c|c|c|c|c|c|c|c|c|}
\hline & \begin{tabular}{|c} 
All cause \\
admission rate \\
(1)
\end{tabular} & $\begin{array}{l}\text { Cardiovascular } \\
\text { admission Rate } \\
\text { (2) }\end{array}$ & $\begin{array}{c}\text { Heart } \\
\text { attack rate } \\
\text { (3) }\end{array}$ & $\begin{array}{l}\text { Injury } \\
\text { admission } \\
\text { rate (4) }\end{array}$ & $\begin{array}{l}\text { Metabolic } \\
\text { adm. rate } \\
\text { (5) }\end{array}$ & $\begin{array}{c}\text { Neoplastic } \\
\text { adm. rate } \\
\text { (6) }\end{array}$ & $\begin{array}{c}\text { Suicide } \\
\text { Attempt rate } \\
\text { (7) }\end{array}$ & $\begin{array}{c}\text { Drug } \\
\text { Overdosing } \\
\text { (8) }\end{array}$ \\
\hline Week of Spring DST & 0.2123 & -0.0664 & -0.0104 & 0.0142 & 0.0348 & $0.2204 * *$ & $0.0230 *$ & 0.0099 \\
\hline$(2 a m \rightarrow 3 a m$ at end of March) & $(0.4274)$ & $(0.0547)$ & $(0.0214)$ & $(0.0145)$ & $(0.0243)$ & $(0.1100)$ & $(0.0124)$ & $(0.0061)$ \\
\hline Week of Fall DST & $-4.9556 * * *$ & $-0.7195 * * *$ & $-0.0882 * * *$ & $-2.7121 * * *$ & $-0.1874 * * *$ & $-0.7357 * * *$ & $-0.0276 * *$ & -0.0044 \\
\hline (3am $\rightarrow 2 a m$ at end of Oct) & (1.1139) & (0.1589) & $(0.02611)$ & $(0.6869)$ & $(0.0385)$ & $(0.1884)$ & $(0.0128)$ & $(0.0055)$ \\
\hline \multicolumn{9}{|l|}{ Controls } \\
\hline County FE & $x$ & $x$ & $x$ & $x$ & $x$ & $x$ & $x$ & $x$ \\
\hline Easter \& Vacation FE & $x$ & $x$ & $x$ & $x$ & $\mathrm{x}$ & $x$ & $x$ & $x$ \\
\hline Day of Week * Month FE & $x$ & $x$ & $x$ & $x$ & $x$ & $x$ & $x$ & $x$ \\
\hline Month*Year Fixed Effects & $x$ & $x$ & $x$ & $x$ & $x$ & $x$ & $x$ & $x$ \\
\hline Linear \& quadr. time trend & $x$ & $x$ & $x$ & $x$ & $x$ & $x$ & $x$ & $x$ \\
\hline Socioeconomic covariates & $x$ & $x$ & $x$ & $x$ & $x$ & $x$ & $x$ & $x$ \\
\hline Mean of dep. variable & 59.77 & 9.53 & 1.59 & 57.56 & 1.73 & 6.59 & 0.32 & 0.09 \\
\hline$R^{2}$ & 0.8469 & 0.5675 & 0.1510 & 0.2067 & 0.3095 & 0.6986 & 0.0179 & 0.0008 \\
\hline$N$ & 336,604 & 336,604 & 336,604 & 336,604 & 336,604 & 336,604 & 336,604 & 336,604 \\
\hline
\end{tabular}

Note: ${ }^{*} p<0.1,{ }^{* *} p<0.05,{ }^{* * *} p<0.01$; standard errors are in parentheses and two-way clustered at the county and date level. The Week of Begin/End DST variables are indicator variables that equal 1 if the interview date is on the DST Sunday or one of the following 6 days. Table B1 lists the dependent variables for as displayed in the column header. Each column is one model as in equation (2). 
Table 5: BRFSS Weekly Approach: Heterogeneity Weekly Effects of Begin and End of DST on Self Assessed Health (SAH) 2001-2010: Testing Effect Heterogeneity

\begin{tabular}{|c|c|c|c|c|c|c|c|c|}
\hline & $\begin{array}{c}(1) \\
\text { Excellent } \\
\text { health }\end{array}$ & $\begin{array}{c}(2) \\
\text { Excellent } \\
\text { health }\end{array}$ & $\begin{array}{c}(3) \\
\text { Excellent } \\
\text { health }\end{array}$ & $\begin{array}{c}(4) \\
\text { Excellent } \\
\text { health }\end{array}$ & $\begin{array}{c}(5) \\
\text { Fair or Poor } \\
\text { health }\end{array}$ & $\begin{array}{c}(6) \\
\text { Fair or Poor } \\
\text { health }\end{array}$ & $\begin{array}{c}(7) \\
\text { Fair or Poor } \\
\text { health }\end{array}$ & $\begin{array}{c}(8) \\
\text { Fair or Poor } \\
\text { health }\end{array}$ \\
\hline Variable & Male & Age $<50$ & Retired & Married & Male & Age $<50$ & Retired & Married \\
\hline Begin DST * Variable & $\begin{array}{l}-0.00014 \\
(0.00640)\end{array}$ & $\begin{array}{c}0.00132 \\
(0.00555)\end{array}$ & $\begin{array}{l}-0.00361 \\
(0.00598)\end{array}$ & $\begin{array}{c}0.00108 \\
(0.00556)\end{array}$ & $\begin{array}{c}0.01471 * * * \\
(0.00520)\end{array}$ & $\begin{array}{l}-0.00674 \\
(0.00481)\end{array}$ & $\begin{array}{c}0.00142 \\
(0.00758)\end{array}$ & $\begin{array}{l}-0.00574 \\
(0.00489)\end{array}$ \\
\hline End DST * Variable & $\begin{array}{c}0.00529 \\
(0.00661)\end{array}$ & $\begin{array}{c}0.01319 * * \\
(0.00543)\end{array}$ & $\begin{array}{l}-0.00457 \\
(0.00514)\end{array}$ & $\begin{array}{l}-0.00035 \\
(0.00590)\end{array}$ & $\begin{array}{l}-0.00773 \\
(0.00583)\end{array}$ & $\begin{array}{c}0.00381 \\
(0.00461)\end{array}$ & $\begin{array}{l}-0.00966 \\
(0.00641)\end{array}$ & $\begin{array}{l}-0.00639 \\
(0.00522)\end{array}$ \\
\hline $\begin{array}{l}\text { Week of Begin DST } \\
(2 \mathrm{am} \rightarrow 3 \mathrm{am} \text { in spring) }\end{array}$ & $\begin{array}{c}0.00318 \\
(0.00431)\end{array}$ & $\begin{array}{c}0.00229 \\
(0.00403)\end{array}$ & $\begin{array}{c}0.00371 \\
(0.00371)\end{array}$ & $\begin{array}{c}0.00248 \\
(0.00506)\end{array}$ & $\begin{array}{l}-0.00634^{*} \\
(0.00341)\end{array}$ & $\begin{array}{c}0.00468 \\
(0.00407)\end{array}$ & $\begin{array}{c}0.00042 \\
(0.00296)\end{array}$ & $\begin{array}{c}0.00410 \\
(0.00474)\end{array}$ \\
\hline $\begin{array}{l}\text { Week of End DST } \\
(2 \mathrm{am} \rightarrow 1 \mathrm{am} \text { in fall) }\end{array}$ & $\begin{array}{c}0.00353 \\
(0.00430)\end{array}$ & $\begin{array}{l}-0.00147 \\
(0.00394)\end{array}$ & $\begin{array}{c}0.00685 \\
(0.00464)\end{array}$ & $\begin{array}{c}0.00623 \\
(0.00528)\end{array}$ & $\begin{array}{c}0.00316 \\
(0.00391)\end{array}$ & $\begin{array}{l}-0.00262 \\
(0.00369)\end{array}$ & $\begin{array}{c}0.00130 \\
(0.00321)\end{array}$ & $\begin{array}{c}0.00337 \\
(0.00499)\end{array}$ \\
\hline \multicolumn{9}{|l|}{ Controls } \\
\hline State FE & $x$ & $x$ & $x$ & $x$ & $x$ & $x$ & $x$ & $x$ \\
\hline Easter and Halloween & $x$ & $x$ & $x$ & $x$ & $x$ & $x$ & $x$ & $x$ \\
\hline Day of Week * Month FE & $x$ & $x$ & $x$ & $x$ & $x$ & $x$ & $x$ & $x$ \\
\hline Month * Year FE & $x$ & $x$ & $x$ & $x$ & $x$ & $x$ & $x$ & $x$ \\
\hline Linear \& quadratic trend & $x$ & $x$ & $x$ & $x$ & $x$ & $x$ & $x$ & $x$ \\
\hline Socioecon. covariates & $x$ & $x$ & $x$ & $x$ & $x$ & $x$ & $x$ & $x$ \\
\hline Mean of dep. Var. & 0.193 & 0.193 & 0.193 & 0.193 & 0.184 & 0.184 & 0.184 & 0.184 \\
\hline $\mathrm{R}^{2}$ & 0.0643 & 0.0644 & 0.0643 & 0.0643 & 0.2041 & 0.2041 & 0.2040 & 0.2041 \\
\hline Obervations & 799,171 & 799,171 & 799,171 & 799,171 & 799,171 & 799,171 & 799,171 & 799,171 \\
\hline
\end{tabular}


Appendix A: BRFSS

Figure A1: BRFSS Observations by Years

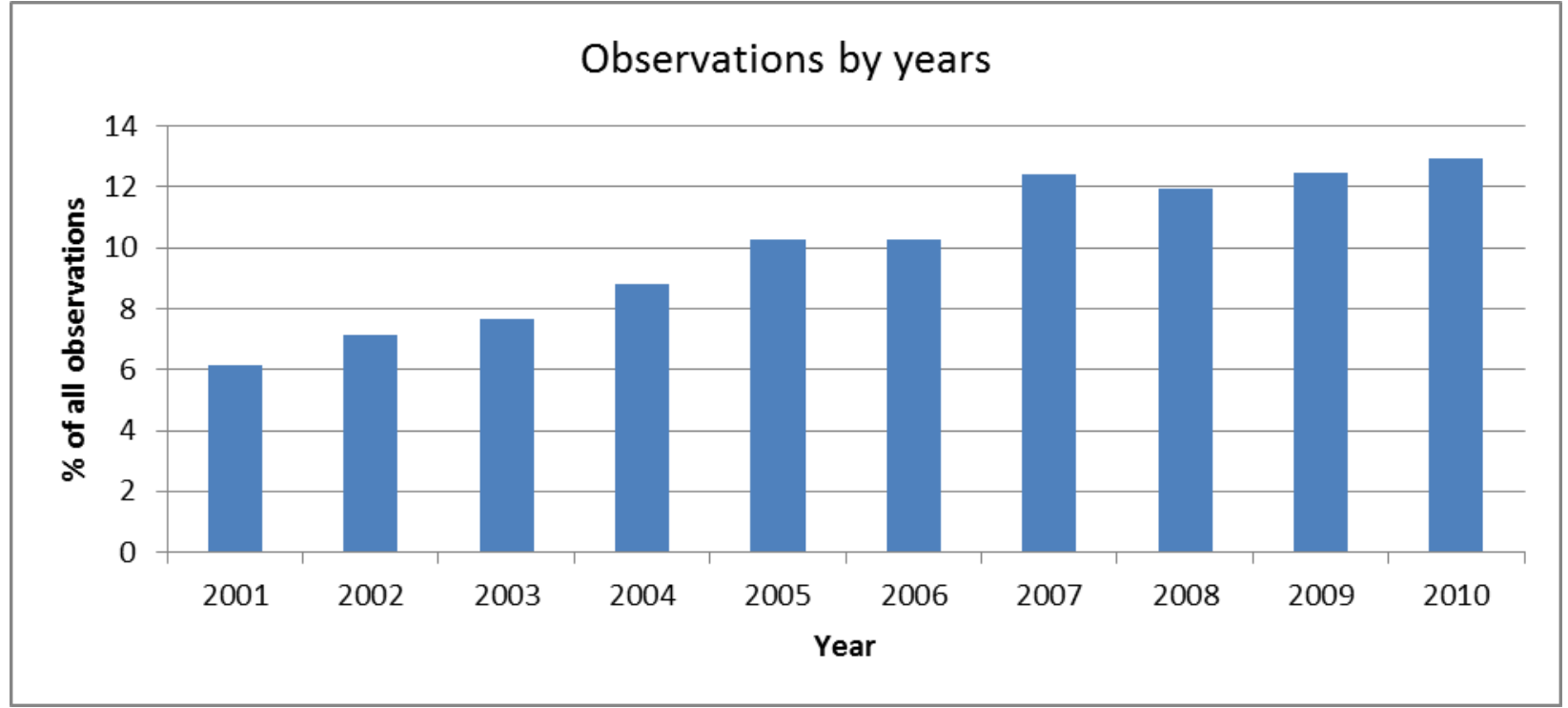

Figure A2: BRFSS Observations by Month-of-Year

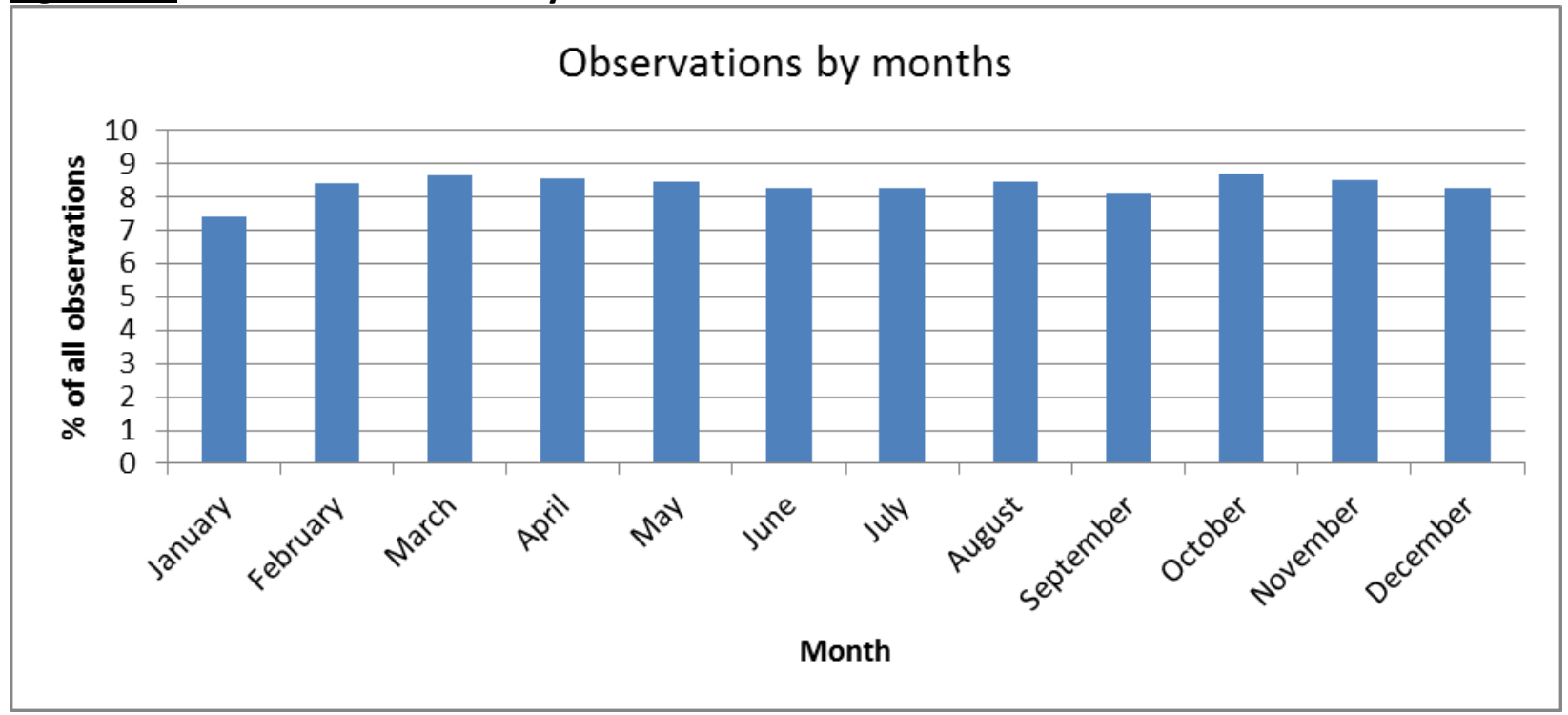


Figure A3a and b: BRFSS Daily Approach with Unweighted Full Sample

Daily Effects of DST on Share of People Reporting Excellent or Very Good Health, 2001-2010

Excellent or Very Good Health

Spring DST

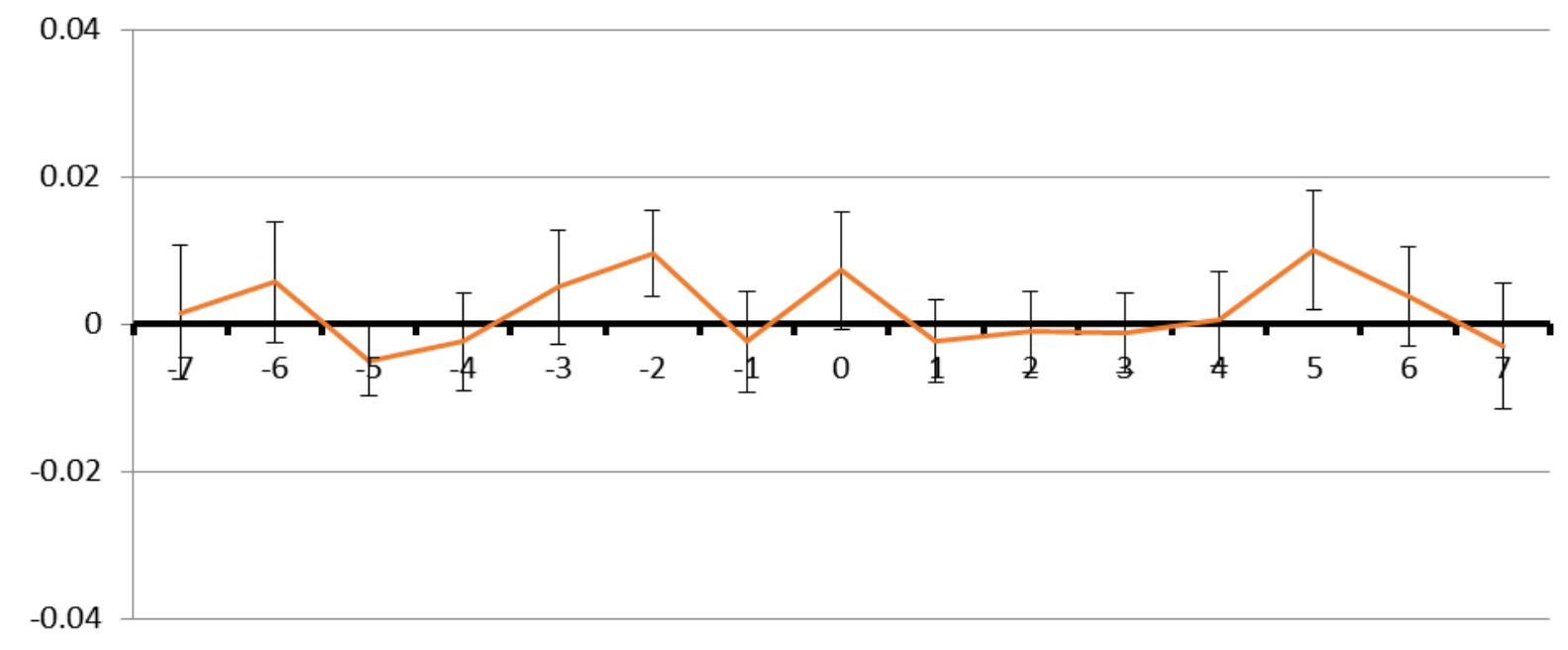

Excellent or Very Good Health

Fall DST

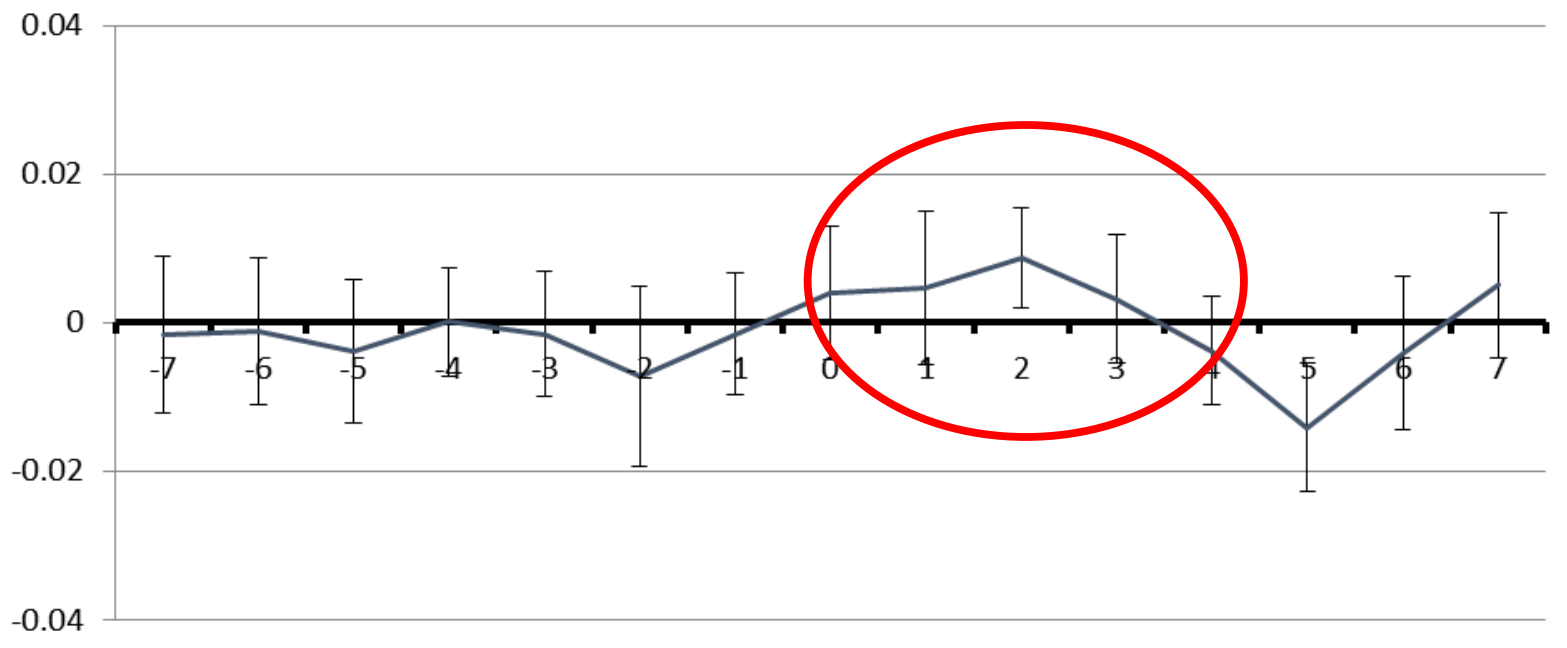


Figure A4a and b: BRFSS Daily Approach with Unweighted Full Sample

Daily Effects of DST on Share of People Reporting Poor Health, 2001-2010

Poor Health

Spring DST

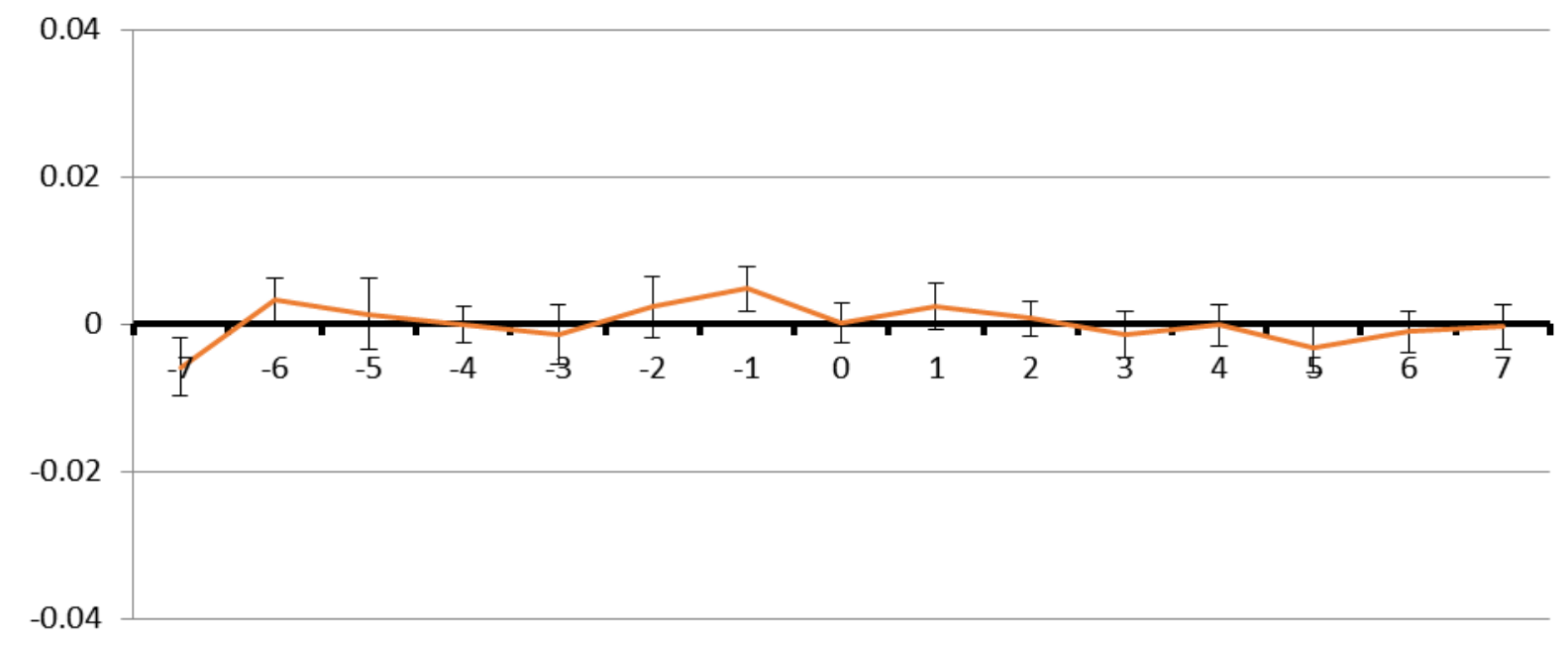

Poor Health

Fall DST

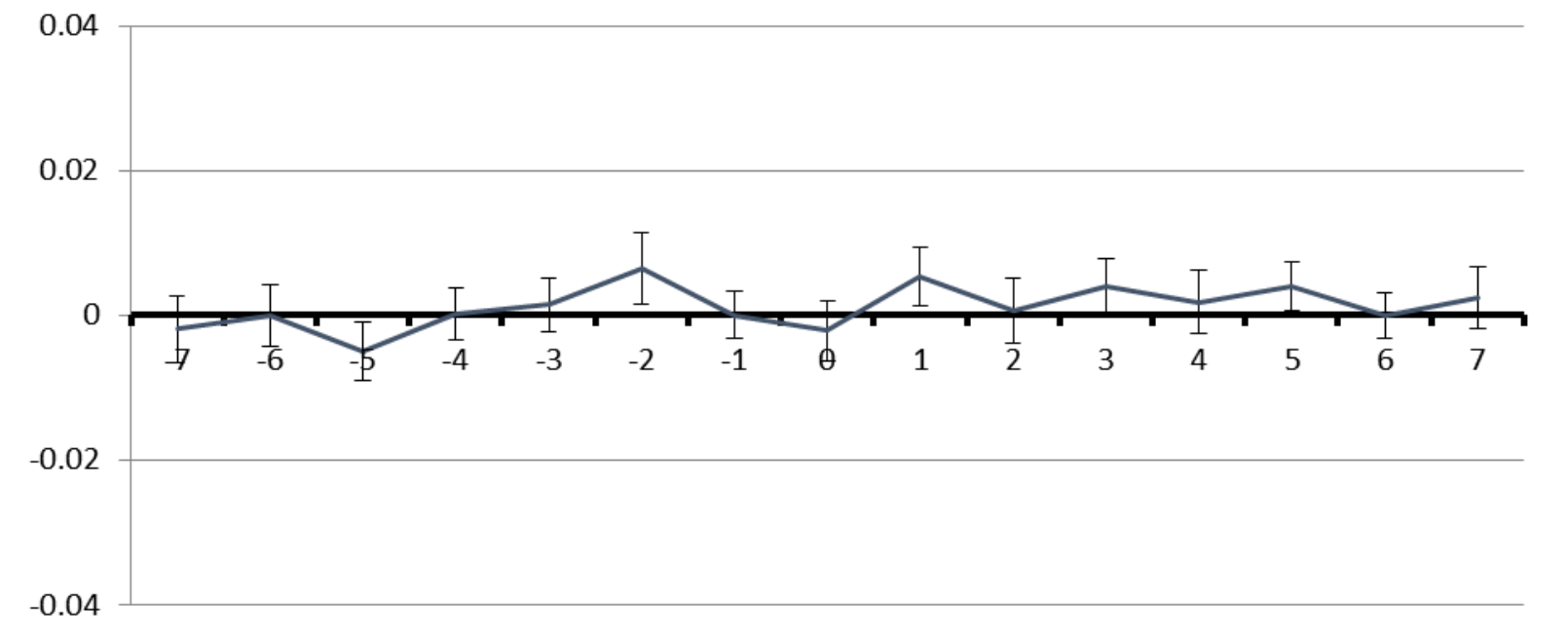


Figure A5a and b: BRFSS Daily Approach

Daily Effects of DST on Share of People Reporting Unintentionally Falling Asleep on at least 1 Day in the Past 30 Days, 2001-2010

At least 1 day: Unintentionally fall asleep Spring DST

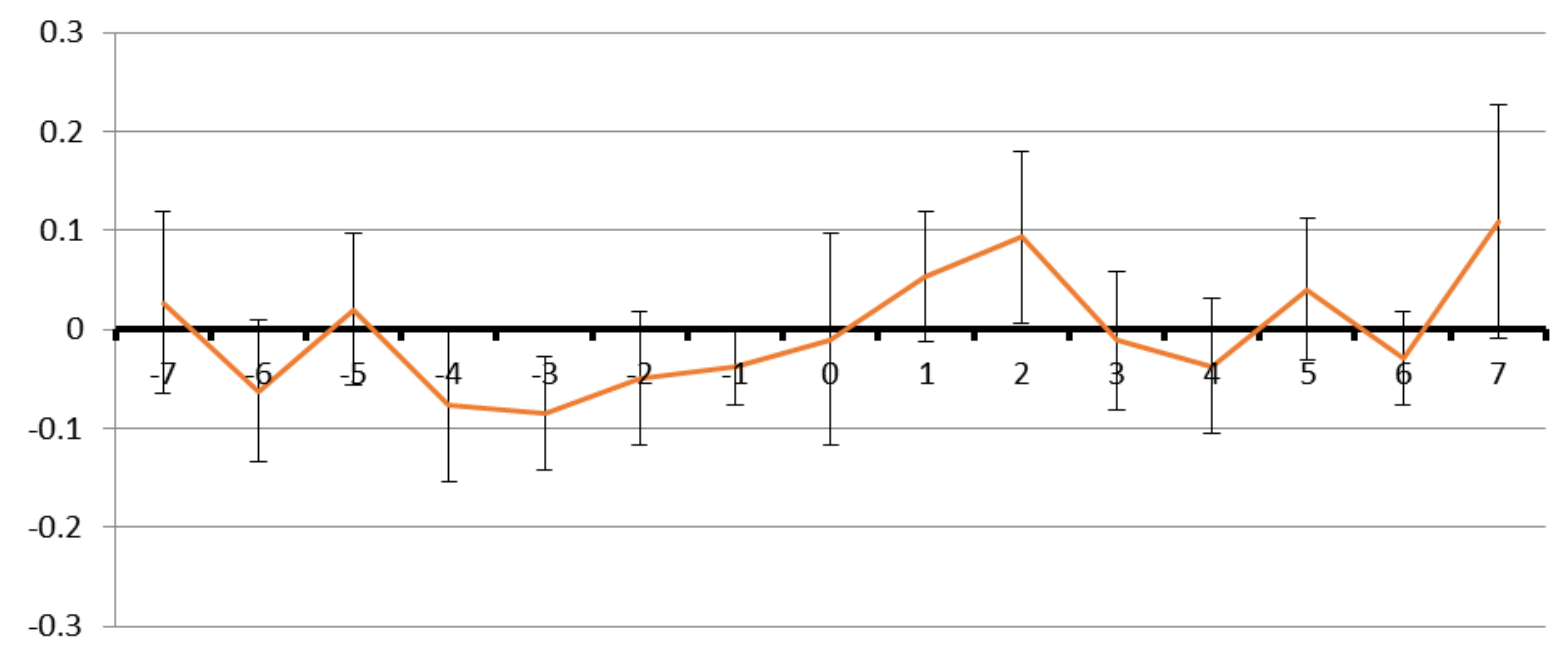

At least 1 day: Unintentionally fall asleep Fall DST

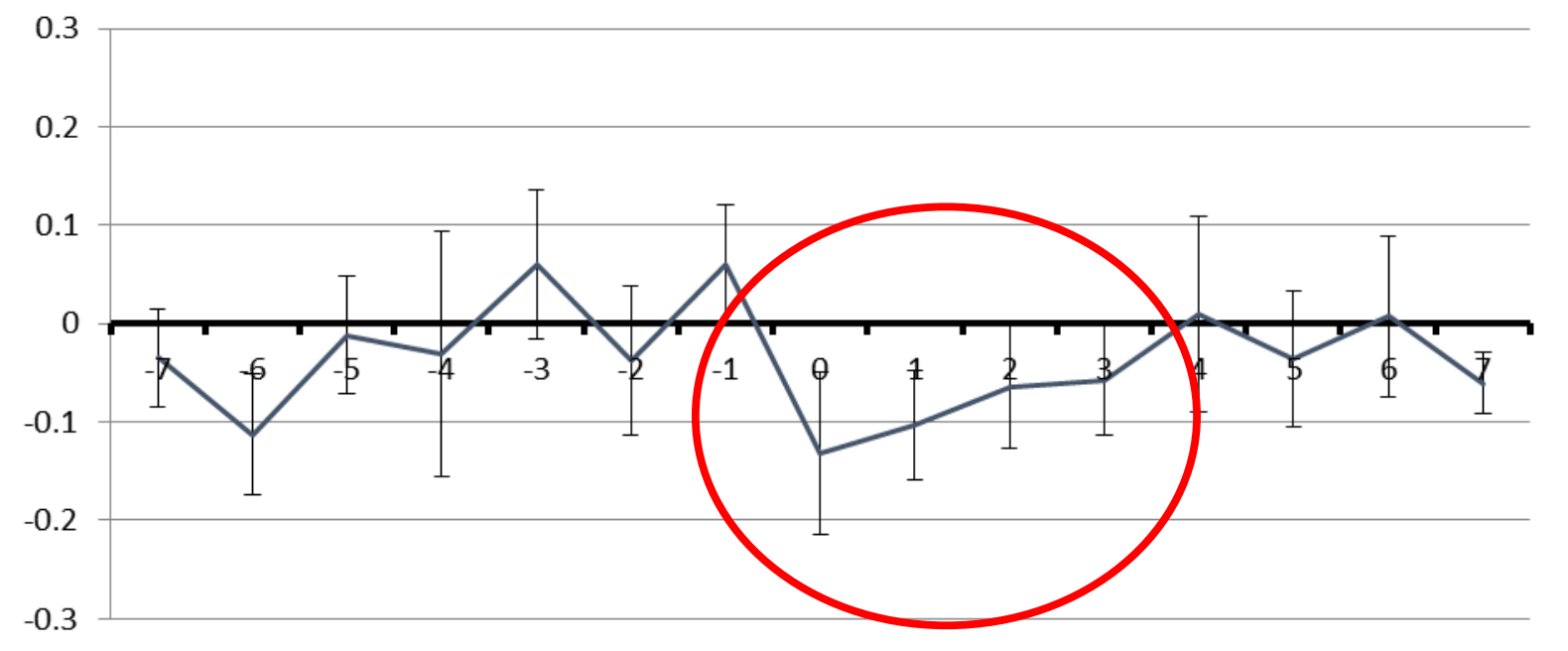


Table A1: BRFSS Descriptive Statistics

\section{Dependent Variables}

General health

Excellent health

Fair or Poor health

Poor physical health

\# days in past 30 days

At least 1 day in past 30 days

Poor mental health

\# days in past 30 days

At least 1 day in past 30 days

Insufficient rest

\# days in past 30 days

At least 1 day in past 30 days

Hours of sleep in past 24 hours

Unintentionally fall asleep

At least 1 day in past 30 days

Nodded off while driving

At least 1 day in past 30 days

\section{Demographic Characteristics}

Age

Female

White

African American

Married

Never married

Number of Children in Household

\section{Educational Characteristics}

Lower Than Secondary Degree

Secondary Degree

Tertiary Degree

Labor Market Characteristics

Employed for wages

Self-employed

Unemployed

Retired

\begin{tabular}{|ccccc|}
\hline Mean & Std. Dev. & Min. & Max. & Obs. \\
\hline & & & & \\
2.532 & 1.106 & 1 & 5 & 799,171 \\
0.193 & 0.395 & 0 & 1 & 799,171 \\
0.184 & 0.387 & 0 & 1 & 799,171
\end{tabular}

$\begin{array}{lllll}4.119 & 8.553 & 0 & 30 & 743,686\end{array}$

$\begin{array}{lllll}0.371 & 0.483 & 0 & 1 & 743,686\end{array}$

$\begin{array}{lllll}3.396 & 7.685 & 0 & 30 & 743,686\end{array}$

$\begin{array}{lllll}0.320 & 0.466 & 0 & 1 & 743,686\end{array}$

$\begin{array}{lllll}7.812 & 10.047 & 0 & 30 & 335,930\end{array}$

$\begin{array}{lllll}0.638 & 0.481 & 0 & 1 & 335,930\end{array}$

$\begin{array}{lllll}7.066 & 1.393 & 1 & 24 & 19,772\end{array}$

$\begin{array}{lllll}0.349 & 0.477 & 0 & 1 & 19,772\end{array}$

$\begin{array}{lllll}0.028 & 0.164 & 0 & 1 & 19,772\end{array}$

$\begin{array}{ccccc}52.049 & 17.444 & 7 & 99 & 799,171 \\ 0.613 & 0.487 & 0 & 1 & 799,171 \\ 0.828 & 0.377 & 0 & 1 & 799,171 \\ 0.087 & 0.282 & 0 & 1 & 799,171 \\ 0.554 & 0.497 & 0 & 1 & 799,171 \\ 0.132 & 0.338 & 0 & 1 & 799,171 \\ 0.633 & 1.082 & 0 & 24 & 799,171\end{array}$

$\begin{array}{lllll}0.037 & 0.189 & 0 & 1 & 799,171 \\ 0.369 & 0.482 & 0 & 1 & 799,171 \\ 0.592 & 0.492 & 0 & 1 & 799,171\end{array}$

Source: BRFSS, 2001-2010, own calculations and illustration. 
Table A2: BRFSS Distribution of Self-Assessed Health (SAH), 2001-2010

\begin{tabular}{ccc}
\hline Responses & Frequency & Percent \\
\hline 1 Excellent & 660,207 & 19.1 \\
2 Very good & $1,107,639$ & 32.05 \\
3 Good & $1,042,752$ & 30.17 \\
4 Fair & 450,411 & 13.03 \\
5 Poor & 194,977 & 5.64 \\
\hline Total & $3,455,986$ & 100 \\
\hline
\end{tabular}

Table A3: BRFSS Balancing Properties between Treatment and Control Weeks, 2001-2010

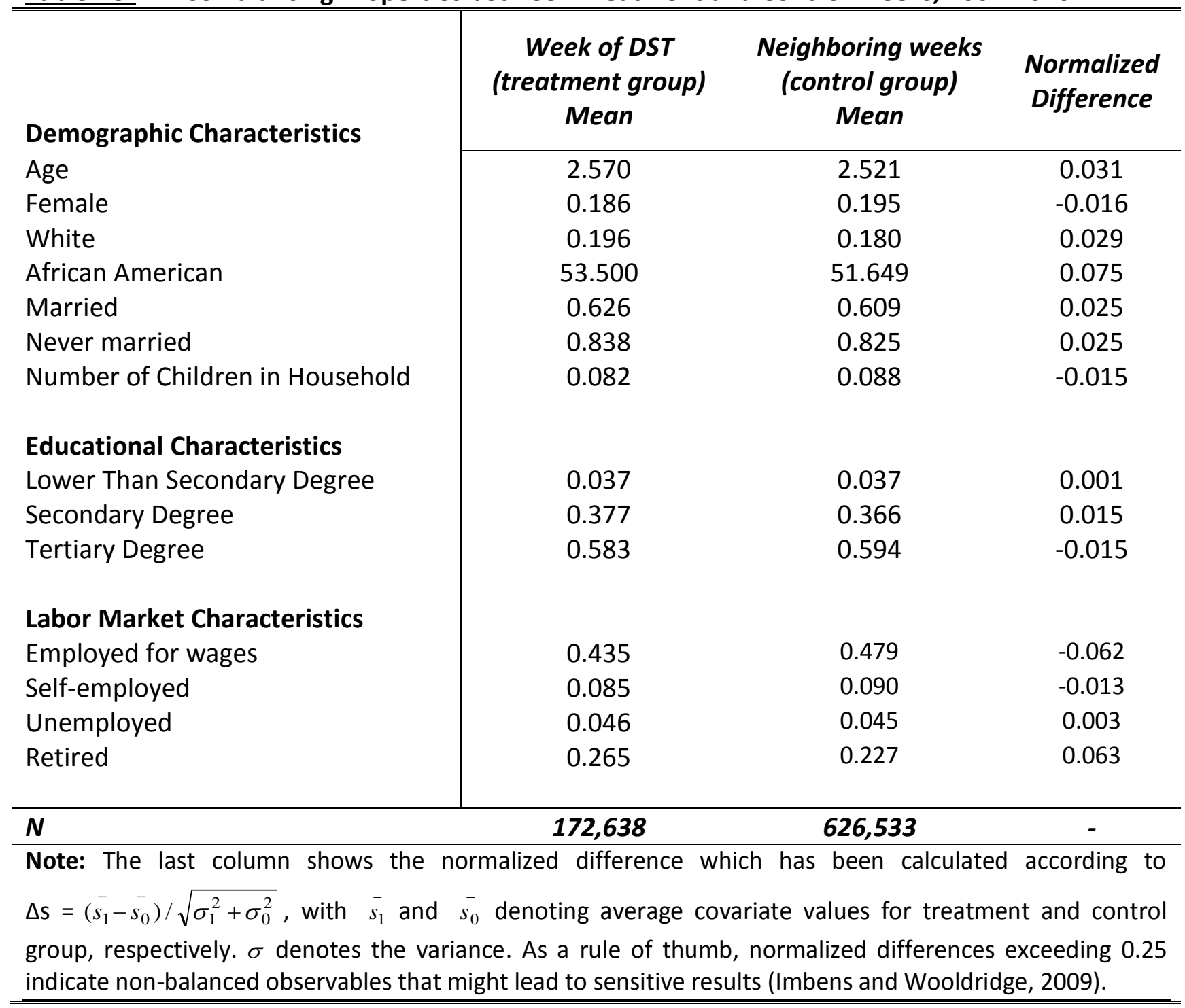


Table A4: BRFSS Weekly Approach

Weekly Effects of DST on SAH 2001-2010: Varying SAH Cut-Offs and Sample Sizes

\begin{tabular}{|c|c|c|c|c|c|}
\hline & $\begin{array}{c}(1) \\
\text { Excellent } \\
\text { health }\end{array}$ & $\begin{array}{c}\text { (2) } \\
\text { Excellent or } \\
\text { VG health }\end{array}$ & $\begin{array}{l}\text { (3) } \\
\text { Excellent or } \\
\text { VG health }\end{array}$ & $\begin{array}{c}(4) \\
\text { Poor } \\
\text { health }\end{array}$ & $\begin{array}{c}\text { (5) } \\
\text { Poor health }\end{array}$ \\
\hline Sample & Full sample & Restricted & Full Sample & Restricted & Full Sample \\
\hline $\begin{array}{l}\text { Week of Begin DST } \\
\text { (2am } \rightarrow \text { 3am in spring) }\end{array}$ & $\begin{array}{c}0.00142 \\
(0.00327)\end{array}$ & $\begin{array}{c}0.00243 \\
(0.00361)\end{array}$ & $\begin{array}{c}0.00282 \\
(0.00349)\end{array}$ & $\begin{array}{l}-0.00066 \\
(0.00148)\end{array}$ & $\begin{array}{l}-0.00065 \\
(0.00148)\end{array}$ \\
\hline $\begin{array}{l}\text { Week of End DST } \\
(2 \mathrm{am} \rightarrow 1 \mathrm{am} \text { in fall) }\end{array}$ & $\begin{array}{c}0.00506 \\
(0.00400)\end{array}$ & $\begin{array}{c}0.00234 \\
(0.00432)\end{array}$ & $\begin{array}{c}0.00234 \\
(0.00419)\end{array}$ & $\begin{array}{c}0.00142 \\
(0.00156)\end{array}$ & $\begin{array}{c}0.00034 \\
(0.00152)\end{array}$ \\
\hline \multicolumn{6}{|l|}{ Controls } \\
\hline State FE & $x$ & $x$ & $x$ & $x$ & $x$ \\
\hline Easter and Halloween & $x$ & $x$ & $x$ & $x$ & $\mathrm{X}$ \\
\hline Day of Week * Month FE & $x$ & $x$ & $x$ & $x$ & $x$ \\
\hline Month * Year FE & $\mathrm{X}$ & $x$ & $\mathrm{X}$ & $x$ & $\mathrm{x}$ \\
\hline $\begin{array}{l}\text { Linear and quadratic } \\
\text { time trend }\end{array}$ & $x$ & $x$ & $x$ & $x$ & $\mathrm{x}$ \\
\hline $\begin{array}{l}\text { Socioeconomic } \\
\text { covariates }\end{array}$ & $x$ & $x$ & $x$ & $x$ & $x$ \\
\hline $\mathrm{R}^{2}$ & 0.0635 & 0.1588 & 0.1600 & 0.1540 & 0.1529 \\
\hline Observations & $3,449,310$ & 799,171 & $3,449,310$ & 799,171 & $3,449,310$ \\
\hline \multicolumn{6}{|c|}{$\begin{array}{l}\text { Notes: Standard errors in parentheses are clustered at the date level. }{ }^{* * *} \text { Significant at } 1 \% \text { level, } * * 5 \%, * \\
10 \% \text {. Regressions are probability-weighted. Week of Begin/End DST are indicator variables equal to } 1 \text { if the } \\
\text { interview is on the DST Sunday or one of the following } 6 \text { days. The dependent variables as described in the } \\
\text { column headers use different cut-offs of the SAH measure as displayed in Table A1 and A2. Each column is } \\
\text { one model as in equation (2). }\end{array}$} \\
\hline
\end{tabular}


(1)

\# Days in past 30 days $w /$ poor physical health
(2)

At least 1 day in past 30 days $w /$ poor physical health
(3)

\# Days in past 30 days $w /$ poor mental health
(4) At least 1 day in past 30 days $w /$ poor mental health

\section{Week of Begin DST}

(2am $\rightarrow$ 3am in spring)

Week of End DST

(2am $\rightarrow$ 1am in fall)

\section{Controls}

State FE

Easter and Halloween

Day of Week * Month FE

Month * Year FE

Linear \&quadr. time trend

Socioeconomic covariates

$\begin{array}{cc}0.01808 & 0.00530 \\ (0.05544) & (0.00425) \\ 0.00238 & -0.00300 \\ (0.06277) & (0.00460)\end{array}$

\section{$X$}

$x$

$x$

$X$

$X$

$X$

0.00169
$(0.00387)$

(0.05932)

0.11521

(0.07557)

$x$
$x$
$x$
$x$
$x$
$x$

0.00236

(0.00449)
(5)

\# Days in past 30 days $w /$

insufficient rest
(6)

At least 1 day in past 30 days $w /$ insufficient rest

\begin{tabular}{lcccccc} 
Mean of dep. Var. & 4.119 & 0.371 & 3.396 & 0.320 & 7.812 & 0.638 \\
$\mathrm{R}^{2}$ & 0.1722 & 0.0559 & 0.0880 & 0.0804 & 0.0696 & 0.1008 \\
\hline Observations & 743,686 & 743,686 & 743,686 & 743,686 & 335,930 & 335,930 \\
\hline
\end{tabular}

Notes: Standard errors in parentheses are clustered at the date level. ${ }^{* * *}$ Significant at $1 \%$ level, $* * 5 \%, * 10 \%$. Regressions are probability-weighted. Week of Begin/End DST are indicator variables equal to 1 if the interview is on the DST Sunday or one of the following 6 days. The column headers describe the dependent variables used in each column; columns (2), (4), and (6) use binary measures, and columns (1), (3), and (5) have values between 0 and 30. The summary statistics of the dependent variables are in Table A1. Each column is one model as in equation (2). 
Table A6: BRFSS Weekly Approach Alternative Outcomes

Weekly Effects of DST 2001-2010: Alternative Outcome Variables

(1)

Hours of sleep in a

24-hour period
(2)

At least 1 in past 30

days: unintentionally falling asleep during day
(3)

At least 1 in past 30

days: Nodded off/ fell asleep while driving

$\begin{array}{lccc}\text { Week of Begin DST } & 0.00661 & 0.03074 & -0.00873 \\ \text { (2am } \rightarrow \text { 3am in spring) } & (0.06822) & (0.02100) & (0.00708) \\ \text { Week of End DST } & 0.09900^{*} & -0.04427^{* *} & -0.00842 \\ \text { (2am } \rightarrow \text { 1am in fall) } & (0.05394) & (0.01895) & (0.00605)\end{array}$

\section{Controls}

State FE

Easter and Halloween

Day of Week * Month FE

Month * Year FE

Linear \& quad. time trend

Socioeconomic covariates

$x$
$x$
$x$
$x$
$x$
$x$

$x$

$x$

$x$

$x$

$x$

$x$

$\mathrm{X}$

\section{$x$}

$x$

$x$

$x$

$\mathrm{X}$

$\begin{array}{llll}\text { Mean of dep. Var. } & 7.07 & 0.35 & 0.03\end{array}$

$\mathrm{R}^{2} \quad 0.0529$

0.0655

0.0284

Observations

19,772

19,772

19,772

Notes: Standard errors in parentheses are clustered at the date level. ${ }^{* * *}$ Significant at $1 \%$ level, ${ }^{* *} 5 \%,{ }^{*}$ $10 \%$. Regressions are probability-weighted. Week of Begin/End DST are indicator variables equal to 1 if the interview is on the DST Sunday or one of the following 6 days. In 2009, six states (Georgia, Hawaii, Illinois, Louisiana, Minnesota, and Wyoming) began to include questions about sleep inadequacy in the BRFSS; this expanded to nine states in 2010 (Arkansas, Connecticut, Delaware, District of Columbia, Hawaii, Minnesota, Missouri, Nevada, and Oregon). The column headers describe the dependent variables used in each column; columns (2) and (3) use binary measures, and column (1) has values between 0 and 24. The summary statistics of the dependent variables are in Table A1. Each column is one model as in equation (2). 
Appendix B: German Hospital Census

Figure B1a and b: Hospital Census Daily Approach: Full Sample

Daily Effects of DST on Total Admissions, Full Sample, 2000-2008

$$
\begin{aligned}
& \text { Total Admissions per 100,000 pop. } \\
& \text { Spring DST, Full Sample }
\end{aligned}
$$

15

10

5

0

$-5$

$-10$

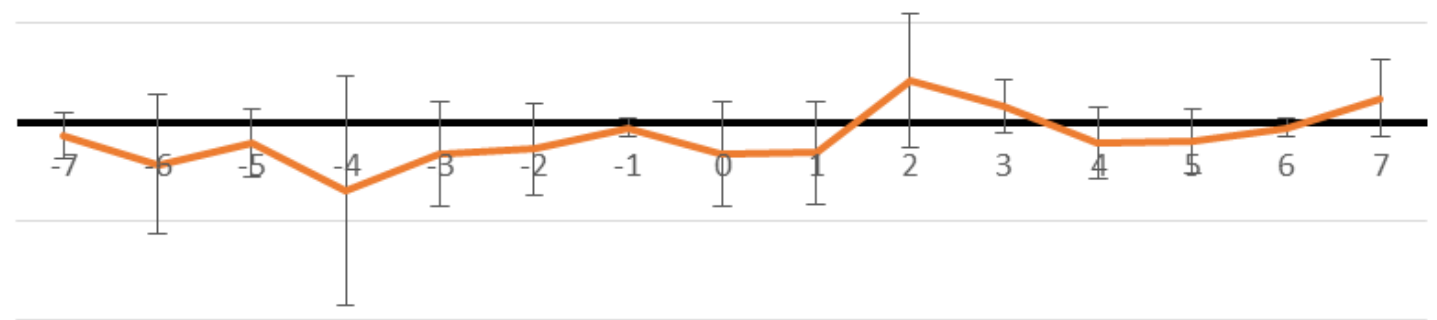

$-15$

$-20$

Total Admissions per 100,000 pop.

Fall DST, Full Sample

15

10

5

0

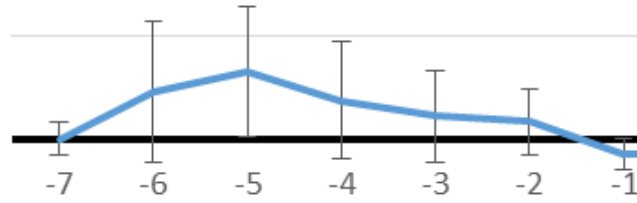

$-5$

$-10$

$-15$

$-20$

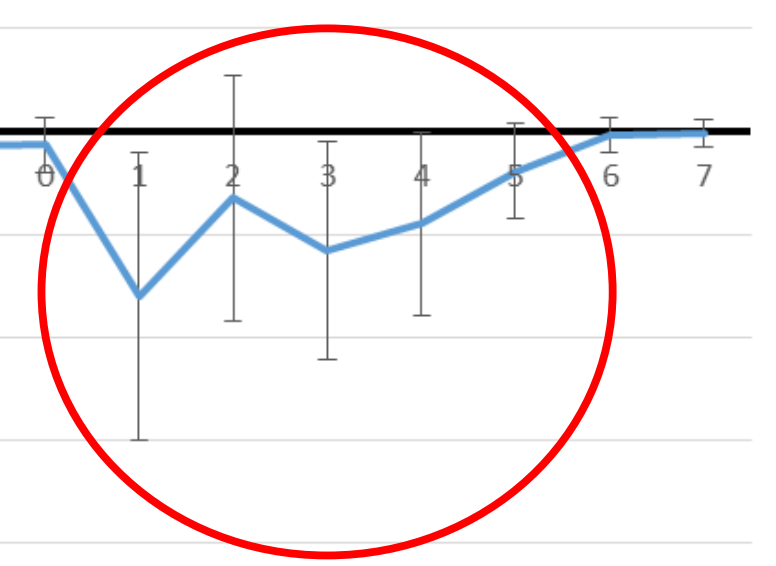


Figure B2a and b: Hospital Census Daily Approach

Daily Effects of DST on Heart Attack, 2000-2008

$$
\begin{gathered}
\text { Heart Attacks per 100,000 pop. } \\
\text { Spring DST }
\end{gathered}
$$

$$
0.2
$$

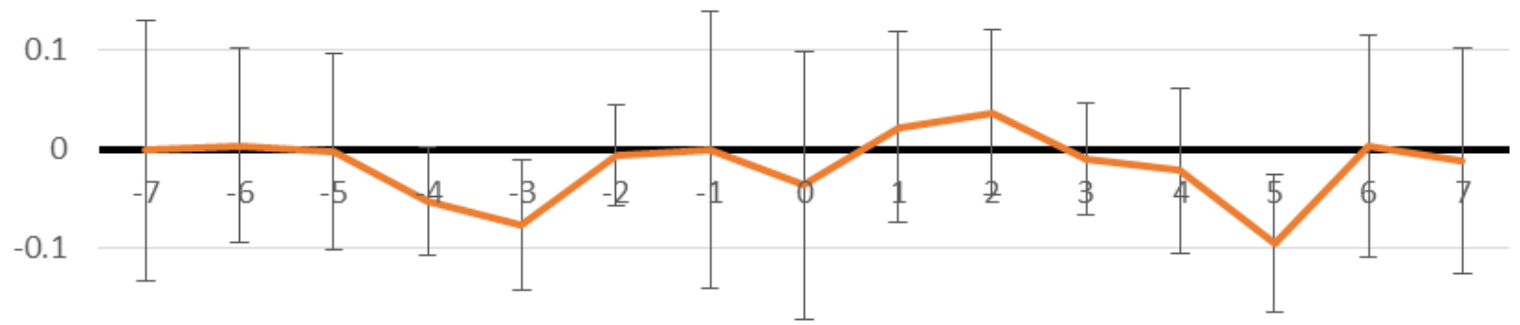

$-0.2$

$-0.3$

$-0.4$

Heart Attacks per 100,000 pop. Fall DST

0.3

0.2

0.1

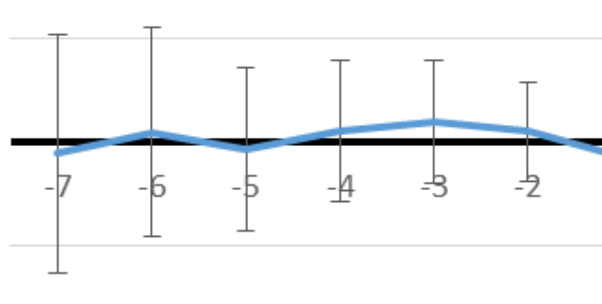

$-0.2$

$-0.3$

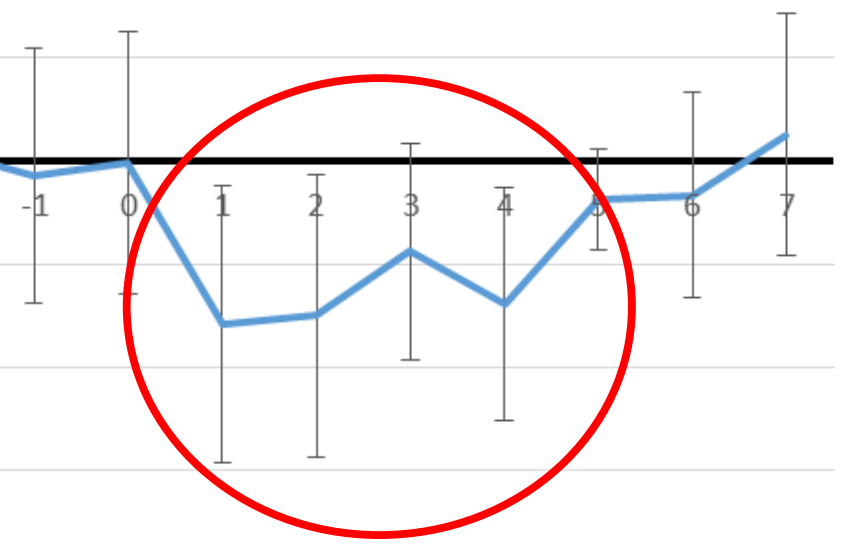

$-0.4$ 
Figure B3a and b: Hospital Census Daily Approach

Daily Effects of DST on Injuries, 2000-2008

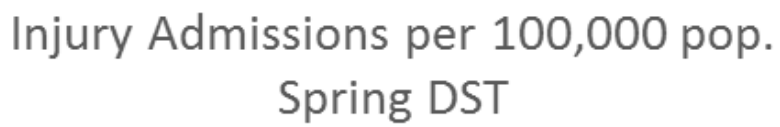

10

8

6

4

$-2$

$-4$

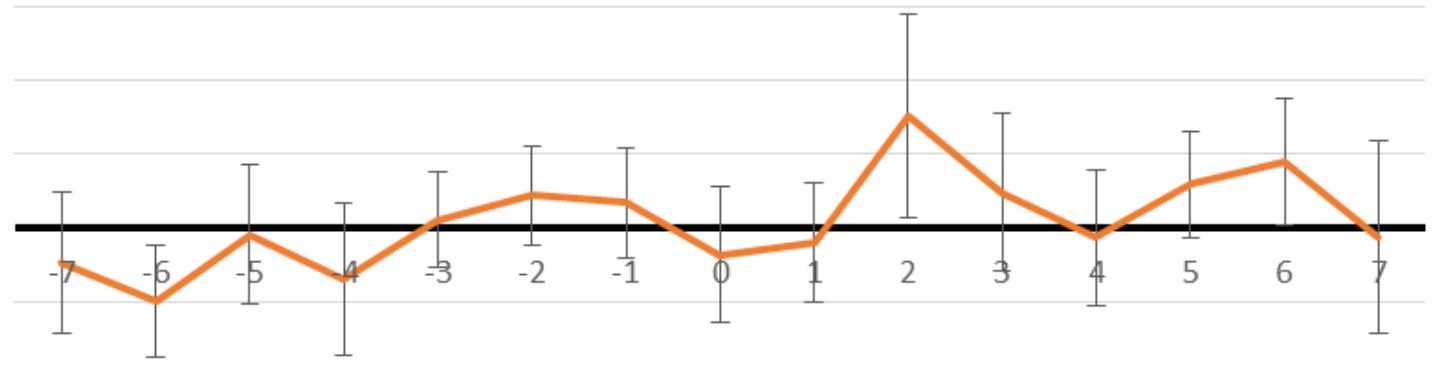

$-8$

$-10$

Injuries Admissions per 100,000 pop.

Fall DST

10

8

6

4

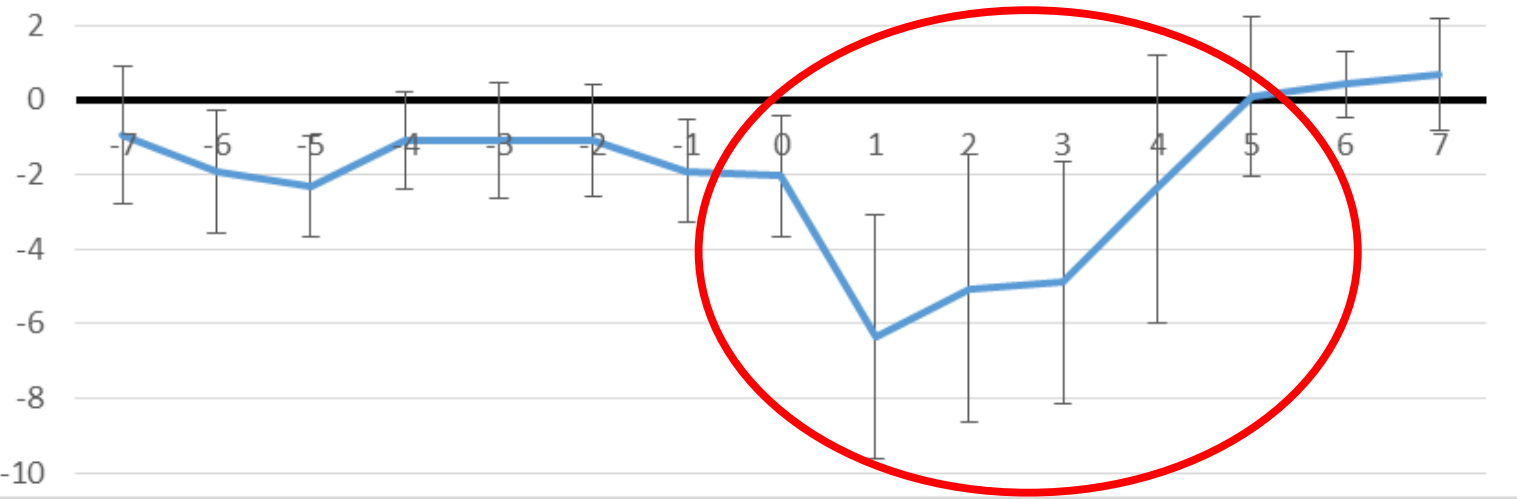


Figure B4a and b: Hospital Census Daily Approach

Daily Effects of DST on Respiratory Admissions, 2000-2008

Respiratory Admissions per 100,000 pop.

Spring DST

0.6

0.4

0.2

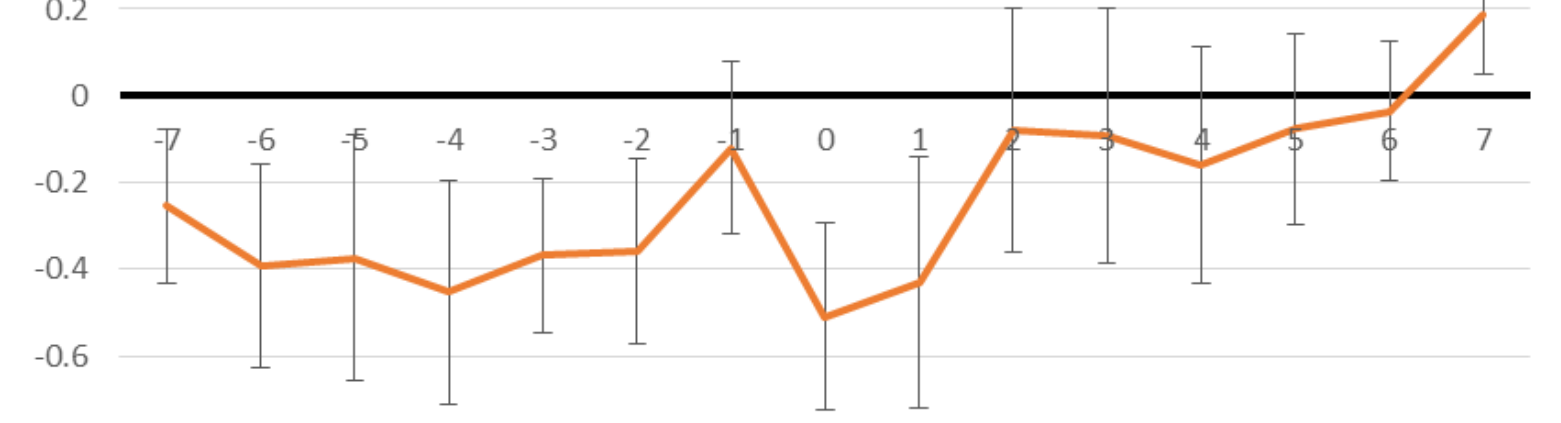

$-0.8$

$-1$

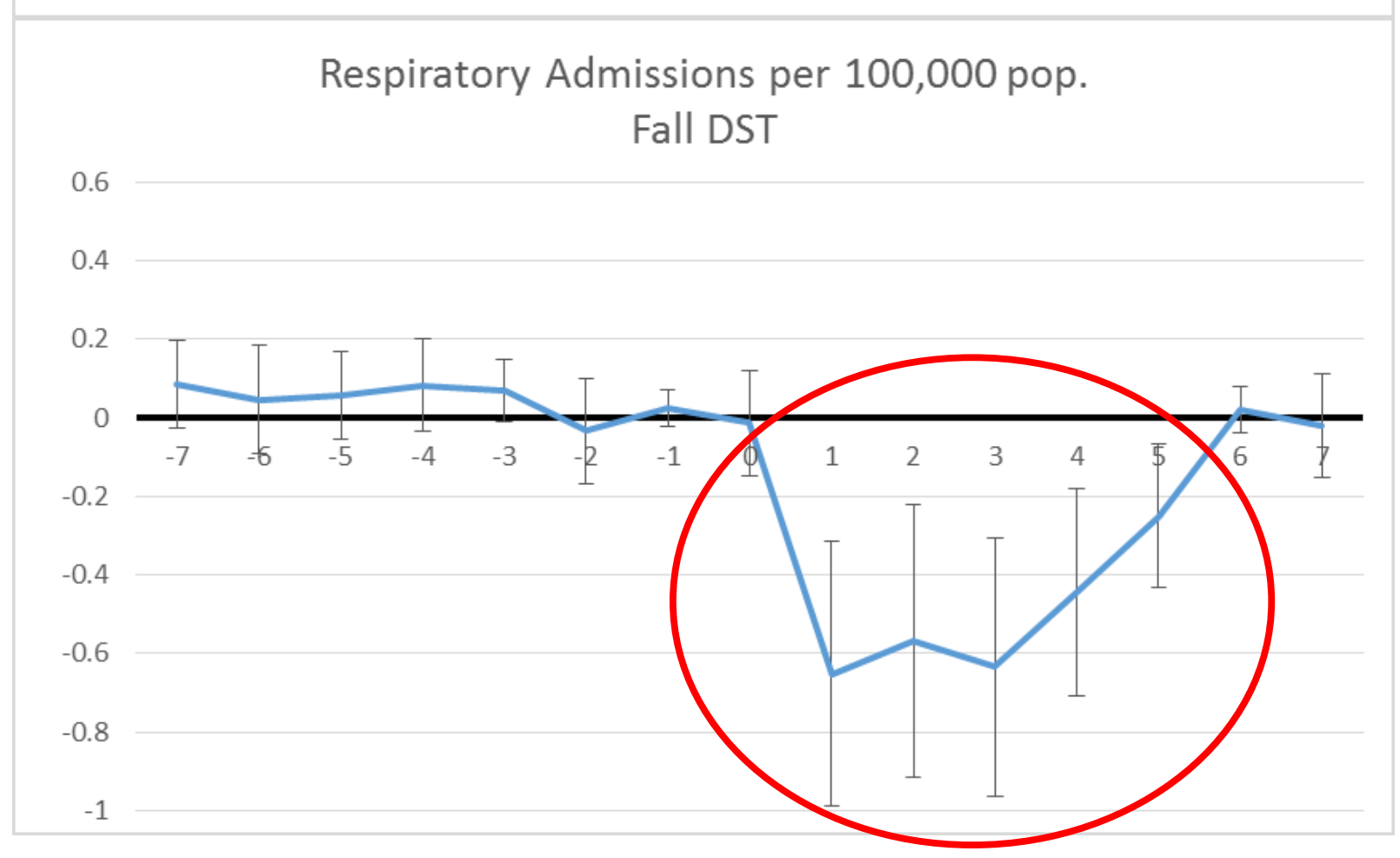


Figure B5a and b: Hospital Census Daily Approach

Daily Effects of DST on Metabolic Admissions, 2000-2008

Metabolic Admissions per 100,000 pop.

Spring DST

0.6

0.4

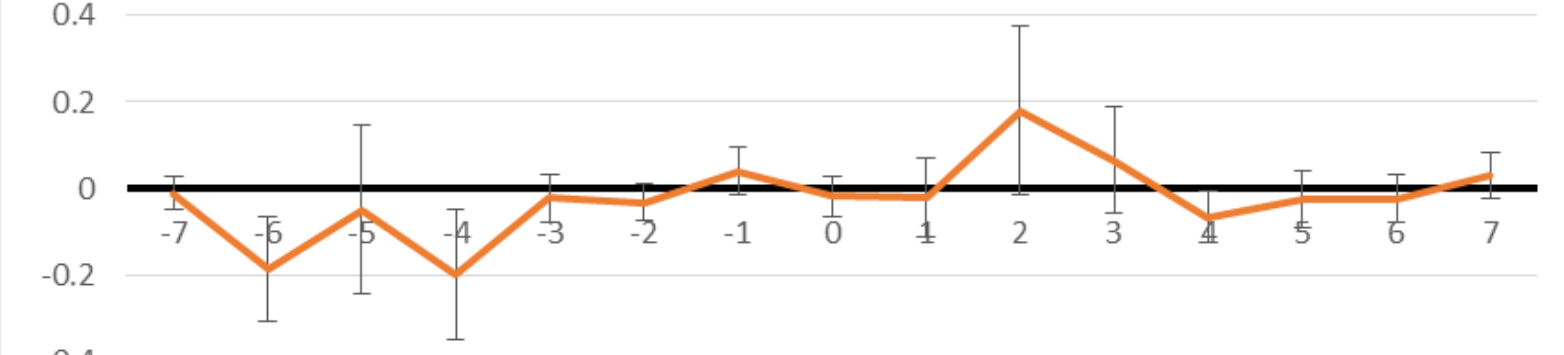

$-0.4$

$-0.6$

$-0.8$

$-1$

Metabolic Admissions per 100,000 pop.

Fall DST

0.6

0.4

0.2

0

$-0.2$

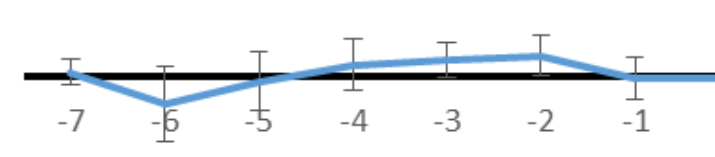

$-0.4$

$-0.6$

$-0.8$

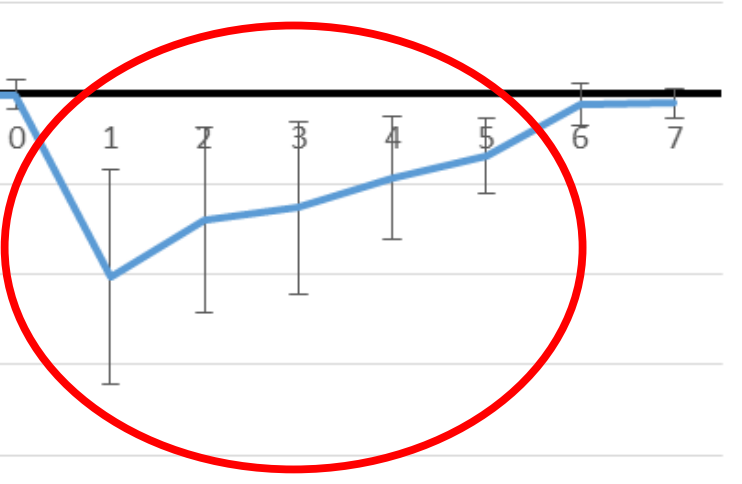

$-1$ 
Figure B6a and b: Hospital Census Daily Approach

Daily Effects of DST on Neoplastic Admissions, 2000-2008

Neoplastic Admissions per 100,000 pop.

Spring DST

$$
2.5
$$

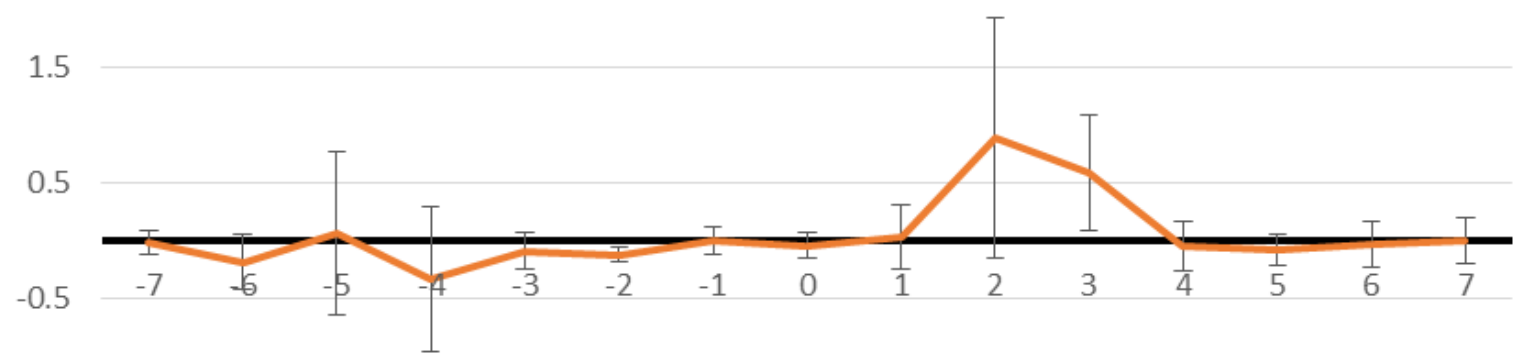

$-1.5$

$-2.5$

$-3.5$

Neoplastic Admissions per 100,000 pop.

$$
\text { Fall DST }
$$

2.5

1.5

0.5

$-0.5$

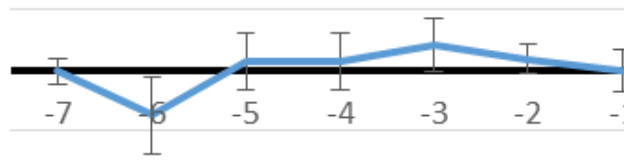

$-1.5$

$-2.5$

$-3.5$

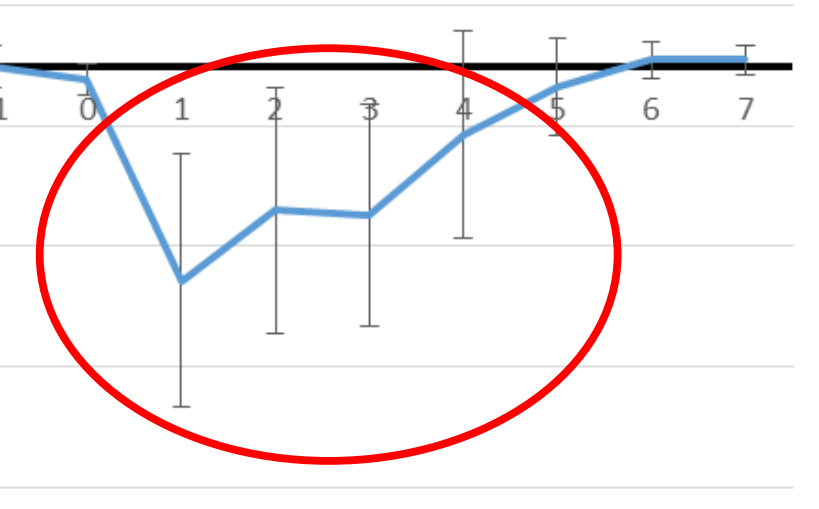


Figure B7a and b: Hospital Census Daily Approach

Daily Effects of DST on Suicide Attempts, 2000-2008

Suicide Attempt Admissions per 100,000 pop.

Spring DST

0.5

0.4

0.3

0.2

0.1

0
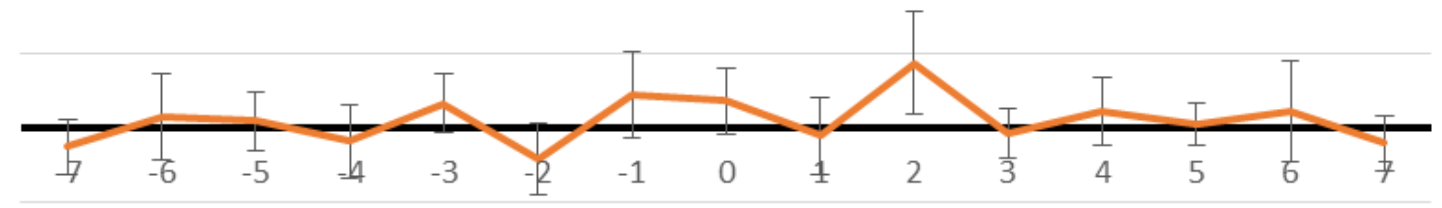

$-0.1$

$-0.2$

$-0.3$

$-0.4$

$-0.5$

Suicide Attempt Admissions per 100,000 pop.

Fall DST

0.5

0.4

0.3

0.2

0.1

0

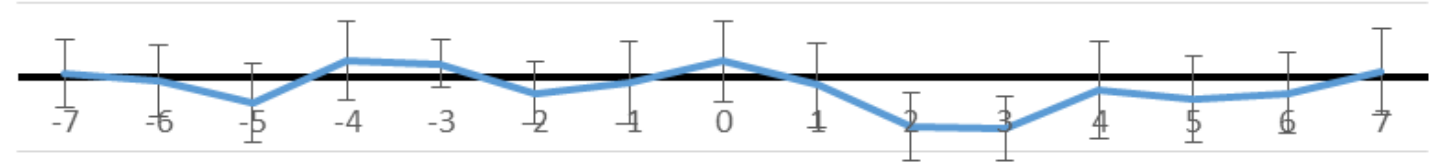

$-0.1$

$-0.2$

$-0.3$

$-0.4$

$-0.5$ 
Figure B8a and b: Hospital Census Daily Approach

Daily Effects of DST on Drug Overdosing, 2000-2008

Drug Overdose Admissions per 100,000 pop.

Spring DST

0.3

0.2

0.1

0

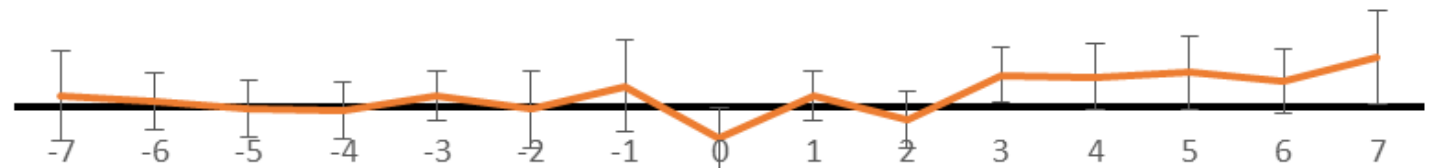

$-0.1$

$-0.2$

$-0.3$

Drug Overdose Admissions per 100,000 pop.

Fall DST

0.3

0.2

0.1

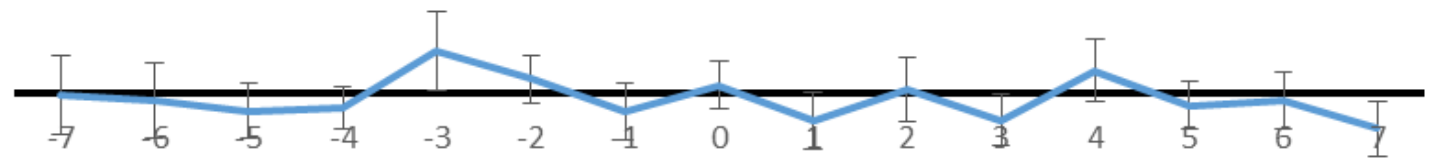

$-0.1$

$-0.2$

$-0.3$ 
Figure B9a and b: Hospital Census Daily Approach

Daily Effects of DST on Infectious Admissions, 2000-2008

$$
\begin{gathered}
\text { Infectious Admissions per 100,000 pop. } \\
\text { Spring DST }
\end{gathered}
$$

0.3

0.2

0.1

$-0.1$

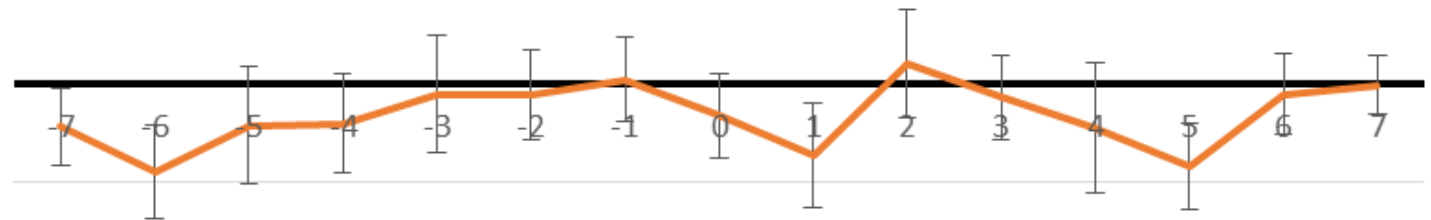

$-0.2$

$-0.3$

$-0.4$

Infectious Admissions per 100,000 pop.

\section{Fall DST}

0.3

0.2

0.1

0

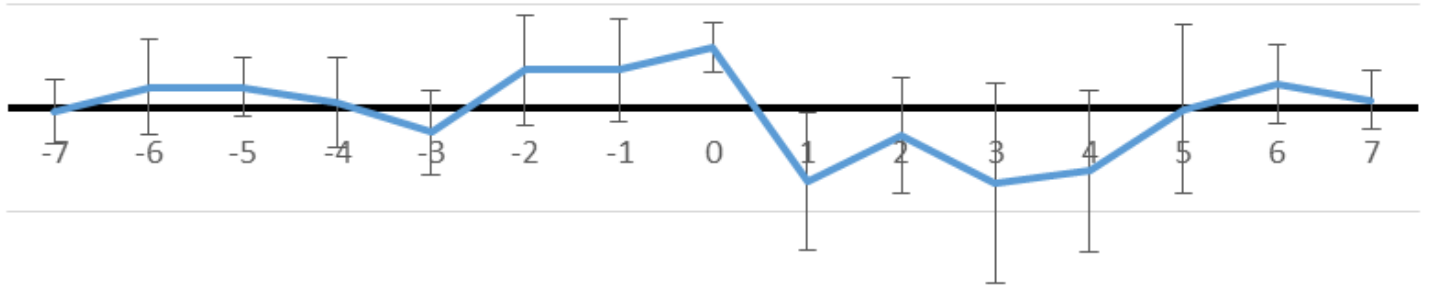

$-0.2$

$-0.3$

$-0.4$ 
Figure B10a and b: Hospital Census Daily Approach

Daily Effects of DST in 22 Summer and 23 Winter Placebo Weeks, 2000-2008

\section{Placebo Spring DST Regressions}
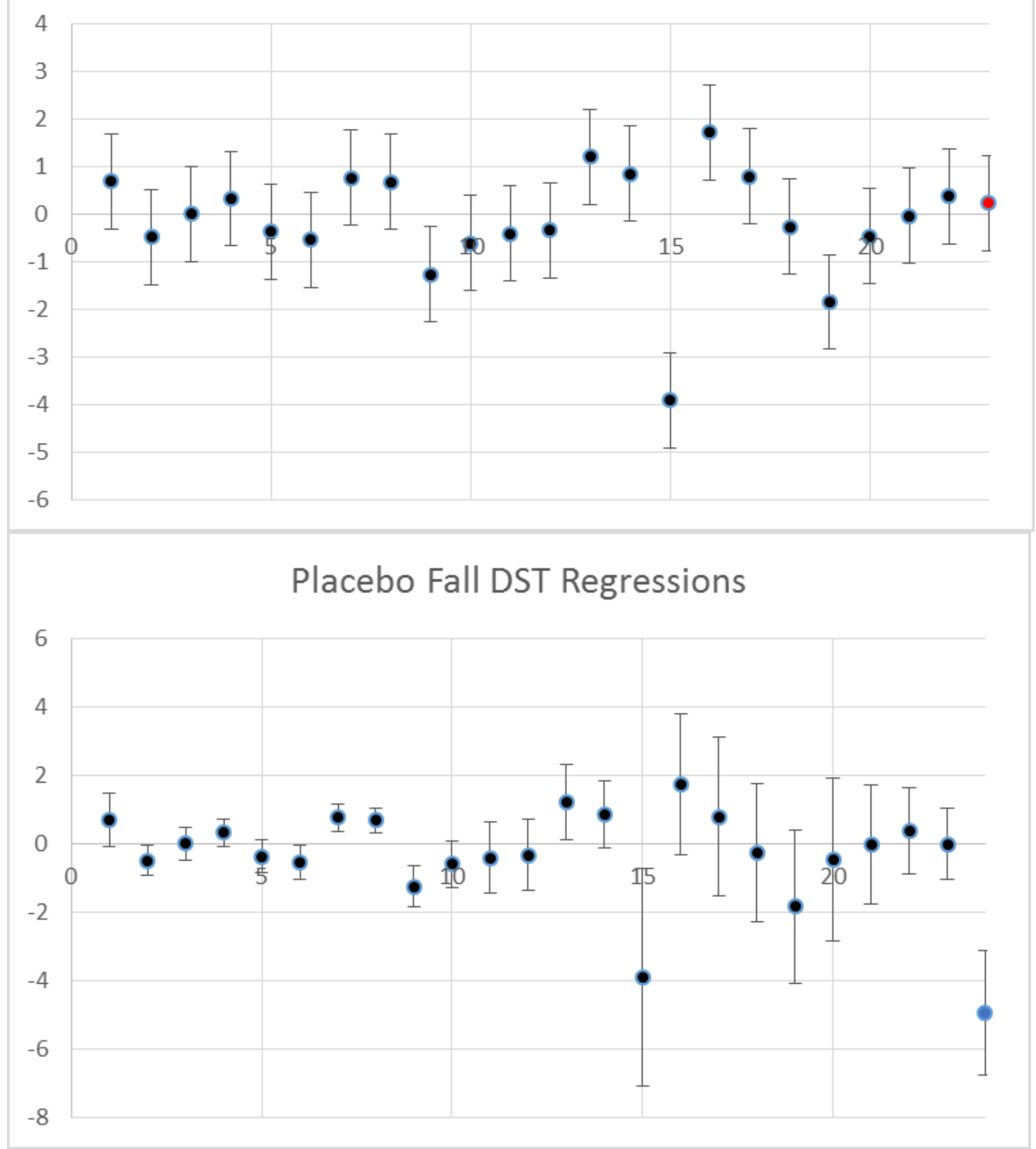

Note: True DST week rightmost estimate. 
Table B1: German Hospital Census Descriptive Statistics

Dependent Variables

Total admission rate per 100,000

Cardiovascular admission rate per 100,000

Heart attack admission rate per 100,000

Injury admission rate per 1 million

Respiratory admission rate per 100,000

Metabolic admission rate per 100,000

Neoplastic admission rate per 100,000

Suicide attempt rate per 1 million

Drug overdosing rate per 1 million

Infectious admission rate per 100,000

\section{Socio-Demographic Individual Controls}

Female

Surgery needed

Died in hospital

Private hospital

Age Group $0-2$ years

Age Group 65-74 years

$>74$ years

\section{Annual County-Level Controls}

Hospital per county

Hospital beds per 10,000

Unemployment rate in county

Physicians per 10,000

GPD per resident (in Euro)

\section{Seasonal Controls}

Holy Thursday, Good Friday, Easter

Sunday, Easter Monday (each)

Easter Vacation

Fall Vacation

Week Begin DST

Week End DST

Mean

Std.Dev

Min.

Max. Obs.

59.7681

25.7333

N/A

N/A

336,604

9.5339

4.9525

N/A

N/A

336,604

1.5909

1.4035

$\mathrm{N} / \mathrm{A}$

$\mathrm{N} / \mathrm{A}$

336,604

56.5571

26.6603

$\mathrm{N} / \mathrm{A}$

N/A

336,604

3.9595

2.5850

$\mathrm{N} / \mathrm{A}$

N/A

336,604

1.7351

1.5909

$\mathrm{N} / \mathrm{A}$

$\mathrm{N} / \mathrm{A}$

336,604

6.5951

5.0857

$\mathrm{N} / \mathrm{A}$

N/A

336,604

0.3219

1.6754

N/A

N/A

336,604

0.0892

0.8594

N/A

$\mathrm{N} / \mathrm{A}$

336,604

1.4069

1.1953

N/A

N/A

336,604

$\begin{array}{ccccc}0.5420 & 0.0671 & 0 & 1 & 336,604 \\ 0.3715 & 0.1478 & 0 & 1 & 336,604 \\ 0.0249 & 0.0230 & 0 & 0.5 & 336,604 \\ 0.1177 & 0.1813 & 0 & 1 & 336,604 \\ 0.0619 & 0.0416 & 0 & 0.5556 & 336,604 \\ \ldots & \ldots & \ldots . & \ldots & 336,604 \\ 0.0161 & 0.0182 & 0 & 0.3333 & 336,604 \\ 0.0034 & 0.0082 & 0 & 0.5 & 336,604\end{array}$

$\begin{array}{ccccc}4.8196 & 5.4690 & 0 & 76 & 336,604 \\ 1204.02 & 1574.54 & 0 & 24,170 & 336,604 \\ 10.37 & 5.29 & 1.6 & 29.3 & 336,604 \\ 153.96 & 53.18 & 69 & 394 & 336,604 \\ 25,235 & 10,219 & 11,282 & 86,728 & 336,604\end{array}$

0.0103

0.1011

1

336,604

$\begin{array}{lllll}0.1210 & 0.3262 & 0 & 1 & 336,604 \\ 0.0977 & 0.2969 & 0 & 1 & 336,604 \\ 0.0862 & 0.2807 & 0 & 1 & 336,604 \\ 0.0862 & 0.2807 & 0 & 1 & 336,604\end{array}$

Source: German Hospital Census 2000-2008, Federal Institute for Research on Building, Urban Affairs and Spatial Development (2012). The hospital admission data are aggregated at the county-day level and normalized per 100,000 population. Consequently, the socio-demographic individual controls are also aggregated at the county-day level. The seasonal controls only vary between days, not across counties. The annual county-level controls vary between the counties and over years, but not within years. 


\section{Linking Hospital Admission Data with Official Weather, Pollution, and Socioeconomic Data}

We merge the Hospital Admission Census with official daily weather and pollution data to exploit additional exogenous variation in ambient conditions that prevail during the time of DST change.

Weather Data. The weather data is provided by the German Meteorological Service (Deutscher Wetterdienst (DWD)). The DWD is a publicly funded federal institution and collects information from hundreds of ambient weather stations which are distributed all over Germany. Daily information on the average temperature, rainfall, hours of sunshine and cloudiness from up to 1,044 monitors and the years 2000 to 2008 are used in this study.

The pollution data are provided by the German Federal Environmental Office (Umweltbundesamt $(U B A))$. The data contains daily pollution measures from up to 1,314 ambient monitors and covers the years 2000 to 2008 . We make use of four pollutants: $\mathrm{CO}, \mathrm{NO}_{2}$, $\mathrm{SO}_{2}$, and $\mathrm{PM}_{10}$.

The point measures of the ambient weather and pollution stations are extrapolated into space using inverse distance weighting. This means that the measures for every county and day are the inverse distance weighted average of all ambient monitors within a radius of $60 \mathrm{~km}$ (37.5 miles) of the county centroid (Hanigan et al. 2006).

Socioeconomic Background Data. Since the Hospital Admission Census only contain gender and sex information, official yearly county-level data are linked to these datasets. As shown in Appendix $A$, the empirical analysis relies on county-level information on GDP per resident, the

unemployment rate, the number of physicians per 10,000 pop., the number of hospitals in county as well as the number of hospital beds per 10,000 pop. 
Table B2: Hospital Census Weekly Approach: Mediating Role of Ambient Conditions

Effects of DST on Total Hospital Admissions, 2000-2008, by Weather and Pollution Conditions

\begin{tabular}{|c|c|c|c|c|c|c|c|c|}
\hline \multirow[b]{2}{*}{ Variable } & \multicolumn{8}{|c|}{ All cause hospital admission rate } \\
\hline & (1) & $(2)$ & (3) & (4) & (5) & (6) & (7) & (8) \\
\hline & Temp. & Rainfall & sunshine & Cloud & $\mathrm{CO}$ & NO2 & SO2 & PM10 \\
\hline Begin DST * Variable & $\begin{array}{c}0.2569 * * \\
(0.1182)\end{array}$ & $\begin{array}{c}-0.1132 * * \\
(0.0564)\end{array}$ & $\begin{array}{c}0.1819 * * \\
(0.0878)\end{array}$ & $\begin{array}{l}-0.2856^{*} \\
(0.1588)\end{array}$ & $\begin{array}{c}0.7647 \\
(1.5761)\end{array}$ & $\begin{array}{c}0.0161 \\
(0.02266)\end{array}$ & $\begin{array}{c}0.4457 * * * \\
(0.1606)\end{array}$ & $\begin{array}{c}0.0803 * * \\
(0.0329)\end{array}$ \\
\hline End DST * Variable & $\begin{array}{l}-0.2378 \\
(0.2329)\end{array}$ & $\begin{array}{c}0.0991 \\
(0.1396)\end{array}$ & $\begin{array}{l}-0.2095 \\
(0.3431)\end{array}$ & $\begin{array}{c}0.4458 \\
(0.5083)\end{array}$ & $\begin{array}{l}8.2131^{* *} \\
(3.5118)\end{array}$ & $\begin{array}{c}0.2071 * * * \\
(0.0552)\end{array}$ & $\begin{array}{c}0.3059 \\
(0.2824)\end{array}$ & $\begin{array}{l}-0.0337 \\
(0.0894)\end{array}$ \\
\hline $\begin{array}{l}\text { Week of Begin DST } \\
(2 a m \rightarrow 3 a m \text { in spring) }\end{array}$ & $\begin{array}{c}-1.7185^{* *} \\
(0.6768)\end{array}$ & $\begin{array}{c}0.3247 \\
(0.4739)\end{array}$ & $\begin{array}{l}-0.8004 \\
(0.5233)\end{array}$ & $\begin{array}{c}1.5348 \\
(0.9807)\end{array}$ & $\begin{array}{l}-0.2364 \\
(0.6605)\end{array}$ & $\begin{array}{c}0.3581 \\
(0.6581)\end{array}$ & $\begin{array}{c}-1.6512^{* * *} \\
(0.5737)\end{array}$ & $\begin{array}{c}-2.1358 * * * \\
(0.7684)\end{array}$ \\
\hline $\begin{array}{l}\text { Week of End DST } \\
\text { (3am } \rightarrow 2 \text { am in fall) }\end{array}$ & $\begin{array}{l}-3.1330 * \\
(1.8671)\end{array}$ & $\begin{array}{c}-5.1829 * * * \\
(1.2059)\end{array}$ & $\begin{array}{c}-4.4812^{* * *} \\
(1.1962)\end{array}$ & $\begin{array}{c}-7.6059 * * \\
(3.3876)\end{array}$ & $\begin{array}{c}-8.8630 * * * \\
(2.2912)\end{array}$ & $\begin{array}{c}-10.75^{* * *} \\
(2.236)\end{array}$ & $\begin{array}{c}-6.0685 * * * \\
(1.3316)\end{array}$ & $\begin{array}{l}-4.1789 * \\
(2.3038)\end{array}$ \\
\hline \multicolumn{9}{|l|}{ Controls } \\
\hline Easter, Halloween, Vacation FE & $x$ & $x$ & $x$ & $\mathrm{X}$ & $x$ & $x$ & $x$ & $x$ \\
\hline Day of Week * Month FE & $x$ & $x$ & $x$ & $x$ & $x$ & $x$ & $x$ & $x$ \\
\hline Month * Year FE & $x$ & $x$ & $x$ & $x$ & $x$ & $x$ & $x$ & $x$ \\
\hline Linear \& quadratic trend & $x$ & $x$ & $x$ & $x$ & $x$ & $x$ & $x$ & $x$ \\
\hline Socioecon. covariates & $x$ & $x$ & $x$ & $x$ & $x$ & $x$ & $x$ & $x$ \\
\hline $\mathrm{R}^{2}$ & 0.8372 & 0.8372 & 0.8373 & 0.8373 & 0.8373 & 0.8375 & 0.8372 & 0.8373 \\
\hline Observations & 336,604 & 336,604 & 336,604 & 336,604 & 336,604 & 336,604 & 336,604 & 336,604 \\
\hline $\begin{array}{l}\text { Notes: Standard errors in parentheses } \\
\text { indicator variables equal to } 1 \text { if the int } \\
\text { rate per } 100,000 \text { pop. at the daily cour } \\
\text { the Hospital Census on a daily county-l}\end{array}$ & $\begin{array}{l}\text { re two-way } \\
\text { jiew is on th } \\
\text { level (App } \\
\text { el basis. Eac }\end{array}$ & $\begin{array}{l}\text { ustered at th } \\
\text { DST Sunday o } \\
\text { idx, Table B1) } \\
\text { column is one }\end{array}$ & $\begin{array}{l}\text { late and cou } \\
\text { ne of the fol } \\
\text { ppendix B d } \\
\text { odel as in ec }\end{array}$ & $\begin{array}{l}\text { y level. } * * * \\
\text { ving } 6 \text { days. } \\
\text { ribes the w } \\
\text { tion (2). }\end{array}$ & $\begin{array}{l}\text { ignificant at } 1 \\
\text { ne dependent } \\
\text { ther and pollc }\end{array}$ & $\begin{array}{l}\% \text { level, } * * 5 \% \\
\text { variable is the } \\
\text { ution measure }\end{array}$ & $\begin{array}{l}* 10 \% . \text { Begi } \\
\text { all cause hos } \\
\text { s and how the }\end{array}$ & $\begin{array}{l}\text { End DST are } \\
\text { al admission } \\
\text { are linked to }\end{array}$ \\
\hline
\end{tabular}


Table B3: Hospital Census Weekly Approach: Effect Heterogeneity

Effects of DST on Total Hospital Admissions, 2000-2008, by County Demographics

\begin{tabular}{|c|c|c|c|c|}
\hline \multirow[b]{2}{*}{ Variable } & \multicolumn{4}{|c|}{ All cause admission rate } \\
\hline & (1) & $(2)$ & (3) & (4) \\
\hline & $\begin{array}{l}\text { Hospital Bed } \\
\text { Density. }\end{array}$ & $\begin{array}{l}\text { Physician } \\
\text { Density }\end{array}$ & $\begin{array}{l}\text { Unemploy } \\
\text { ment Rate }\end{array}$ & $\begin{array}{l}\text { GDP per } \\
\text { capita }\end{array}$ \\
\hline Begin DST * Variable & $\begin{array}{c}0.2569 * * \\
(0.1182)\end{array}$ & $\begin{array}{c}-0.1132^{* *} \\
(0.0564)\end{array}$ & $\begin{array}{c}0.1819 * * \\
(0.0878)\end{array}$ & $\begin{array}{l}-0.2856^{*} \\
(0.1588)\end{array}$ \\
\hline End DST * Variable & $\begin{array}{l}-0.2378 \\
(0.2329)\end{array}$ & $\begin{array}{c}0.0991 \\
(0.1396)\end{array}$ & $\begin{array}{l}-0.2095 \\
(0.3431)\end{array}$ & $\begin{array}{c}0.4458 \\
(0.5083)\end{array}$ \\
\hline $\begin{array}{l}\text { Week of Begin DST } \\
\text { (2am } \rightarrow \text { 3am in spring) }\end{array}$ & $\begin{array}{c}-1.7185^{* *} \\
(0.6768)\end{array}$ & $\begin{array}{c}0.3247 \\
(0.4739)\end{array}$ & $\begin{array}{l}-0.8004 \\
(0.5233)\end{array}$ & $\begin{array}{c}1.5348 \\
(0.9807)\end{array}$ \\
\hline $\begin{array}{l}\text { Week of End DST } \\
\text { (3am } \rightarrow 2 \text { am in fall) }\end{array}$ & $\begin{array}{l}-3.1330 * \\
(1.8671)\end{array}$ & $\begin{array}{c}-5.1829 * * * \\
(1.2059)\end{array}$ & $\begin{array}{c}-4.4812 * * * \\
(1.1962)\end{array}$ & $\begin{array}{c}-7.6059 * * \\
(3.3876)\end{array}$ \\
\hline \multicolumn{5}{|l|}{ Controls } \\
\hline Easter, Halloween, Vacation FE & $x$ & $x$ & $\mathrm{X}$ & $x$ \\
\hline Day of Week * Month FE & $x$ & $x$ & $x$ & $x$ \\
\hline Month * Year FE & $x$ & $x$ & $\mathrm{X}$ & $x$ \\
\hline Linear \& quadratic trend & $x$ & $x$ & $x$ & $\mathrm{X}$ \\
\hline Socioecon. covariates & $x$ & $\mathrm{X}$ & $\mathrm{X}$ & $\mathrm{X}$ \\
\hline $\mathrm{R}^{2}$ & 0.8372 & 0.8372 & 0.8373 & 0.8373 \\
\hline Observations & 336,604 & 336,604 & 336,604 & 336,604 \\
\hline \multicolumn{5}{|c|}{$\begin{array}{l}\text { Notes: Standard errors in parentheses are two-way clustered at the date and county level. } \\
* * * \text { Significant at } 1 \% \text { level, } * * 5 \%, * 10 \% \text {. Begin/End DST are indicator variables equal to } 1 \text { if the } \\
\text { interview is on the DST Sunday or one of the following } 6 \text { days. The dependent variable is the all } \\
\text { cause hospital admission rate per } 100,000 \text { pop. at the daily county level. Table B1 lists the } \\
\text { stratifying variables for the interaction terms as displayed below the column header. Each column is } \\
\text { one model as in equation (2). }\end{array}$} \\
\hline
\end{tabular}

